\title{
Validation of a High-Resolution Regional Climate Model for the Alpine Region and Effects of a Subgrid-Scale Topography and Land Use Representation
}

\author{
E.-S. IM, E. COPPOLA, F. GIORgI, AND X. BI \\ Earth System Physics, International Centre for Theoretical Physics, Trieste, Italy
}

(Manuscript received 28 May 2009, in final form 26 October 2009)

\begin{abstract}
A mosaic-type parameterization of subgrid-scale topography and land use (SubBATS) is applied for a high-resolution regional climate simulation over the Alpine region with a regional climate model (RegCM3). The model coarse-gridcell size in the control simulation is $15 \mathrm{~km}$ while the subgridcell size is $3 \mathrm{~km}$. The parameterization requires disaggregation of atmospheric variables from the coarse grid to the subgrid and aggregation of surface fluxes from the subgrid to the coarse grid. Two 10-yr simulations (1983-92) are intercompared, one without (CONT) and one with (SUB) the subgrid scheme. The authors first validate the CONT simulation, showing that it produces good quality temperature and precipitation statistics, showing in particular a good performance compared to previous runs of this region. The subgrid scheme produces much finer detail of temperature and snow distribution following the topographic disaggregation. It also tends to form and melt snow more accurately in response to the heterogeneous characteristics of topography. In particular, validation against station observations shows that the SUB simulation improves the model simulation of the surface hydrologic cycle, in particular snow and runoff, especially at high-elevation sites. Finally, two experiments explore the model sensitivity to different subgrid disaggregation assumptions, namely, the temperature lapse rate and an empirical elevation-based disaggregation of precipitation.
\end{abstract}

\section{Introduction}

Land surface and topography (defined as surface elevation) are among the strongest forcings that influence regional and local climates (Dickinson 1995: Pielke and Avissar 1990). In fact, complex topographical features and land surface characteristics can locally modulate the climate change signal by regulating the land-atmosphere exchanges of heat, water, and momentum, modifying the structure of traveling synoptic systems, and triggering convection and mesoscale organized circulations (e.g., Giorgi and Mearns 1991; Feddema et al. 2005; Giorgi and Avissar 1997; Pielke 2001). It is therefore important to account for the effects of complex topography and land use in climate simulations.

To fully capture the complexity of the topography and land surface structure, however, a resolution is required that is well beyond that achievable with present day global and even regional climate models used in multidecadal to

Corresponding author address: Dr. Eun-Soon Im, Earth System Physics, International Centre for Theoretical Physics, Strada Costiera, 11, 34151, Trieste, Italy.

E-mail: eim@ictp.it centennial simulations. For this reason, different methodologies have been proposed to account for subgridscale topography and land use effects, such as multiple nesting (Leung and Qian 2003; Christensen et al. 1998; Im et al. 2006) or parameterization of subgrid-scale processes (Giorgi and Avissar 1997). The latter type of approach provides a first-order representation of finescale land surface processes, which allows us to bridge the scale gap between climate information and local application without use of a full dynamical model. It can thus be especially useful for long-term climate integrations.

Perhaps the most popular approach for representing subgrid-scale heterogeneity is the so-called mosaic technique, in which a climate model grid box is divided into a set of subgrid "tiles." These tiles can be based on homogeneous land surface categories (Avissar and Pielke 1989), homogenous topography categories (Leung and Ghan 1995), or regular subgrid boxes each characterized by its own land use type and elevation (Seth et al. 1994). The advantages and limitations of these different ways of representing land heterogeneity are discussed by Giorgi and Avissar (1997). In particular, Giorgi et al. (2003, hereafter referred to as G03) implemented the subgrid scheme of Seth et al. (1994) within the framework of a 
regional climate model [the RegCM2 described by Giorgi et al. (1993a,b)] and applied it to a test simulation over the entire European region, showing that the subgrid scheme improved various aspects of the surface hydrological budget. This same subgrid model configuration was also used by Dimri (2009) for a domain covering northern India and by Gao and collaborators for a small domain covering the Three Gorge River Dam (X. Gao 2009, personal communication).

The spatial resolution used in the European runs by G03 was still relatively coarse with a model grid size of $60 \mathrm{~km}$ and a regular subgrid size of $10 \mathrm{~km}$. Especially for morphologically complex areas such as the Alps, a higher resolution may still be required to provide useful information for input into basin hydrology studies. As part of the new European Union project, Assessing Climate Impacts on the Quantity and Quality of Water (ACQWA; http://www.acqwa.ch/), aimed at assessing the effects of climate change on the hydrologic cycle of the Alpine region, an upgraded and higher-resolution version of the model used by G03 has been developed and tested for a domain encompassing the Alpine and central Mediterranean areas. This region is characterized by a pronounced finescale variability of both elevation and land surface characteristics, and thus it is optimal for testing and applying our subgrid scheme. The dynamical model, an upgraded version of the RegCM [the RegCM3 described by Pal et al. (2007)], employs a much higher resolution than in G03 a model grid spacing of $15 \mathrm{~km}$ with a land surface subgrid of 3-km resolution. In this paper we first present a validation of this regional model configuration via a decadal simulation driven at the lateral boundaries by analyses of observations. We then analyze the effects of the subgrid land scheme on the simulated surface hydrologic cycle by comparing simulations with and without the land subgrid representation. Finally, we assess the sensitivity of the subgrid scheme to different assumptions in its parametric representations.

\section{Model and experiment design}

\section{a. Regional climate model}

The regional climate model used in this study is the latest version of the International Centre for Theoretical Physics (ICTP) regional climate model (RegCM3) described by Pal et al. (2007). It is an upgraded version of the model originally developed by Giorgi et al. (1993a,b) and improved as discussed by Giorgi and Mearns (1999). The physical parameterizations employed in the simulations include the radiative transfer package of the National Center for Atmospheric Research (NCAR) Community Climate Model, version 3 (Kiehl et al. 1996), the nonlocal boundary layer scheme of Holtslag et al. (1990), the mass-flux cumulus cloud scheme of Grell (1993), and the resolvable-scale cloud and precipitation scheme of Pal et al. (2000). Surface physics processes are described by the Biosphere-Atmosphere Transfer Scheme (BATS) land surface scheme (Dickinson et al. 1993), which is a land surface package designed to describe the role of vegetation and interactive soil moisture in modifying the surface-atmosphere exchanges of momentum, energy, and water vapor. In particular, snow depth is prognostically calculated from snowfall, snowmelt, and sublimation by using a one-layer snow model. The effect of snow age on albedo is considered using a parametric formula, while the radiative solar and infrared heating, sublimationcondensation, and sensible heat exchange with the underlying soil and overlying atmosphere contribute to the energy budget of the snow layer. Precipitation is assumed to fall in the form of snow if the temperature of the lowest atmospheric model layer (about $25 \mathrm{~m}$ from the surface) is lower than $1.8^{\circ} \mathrm{C}$. As a result, the response of snow is nonlinear, since snow formation and melting are regulated by processes that are essentially step functions of temperature thresholds.

\section{b. Subgrid land surface parameterization}

The mosaic-type parameterization of Seth et al. (1994, hereafter referred to as SubBATS) is implemented within the RegCM3 as documented by G03. In the SubBATS scheme, each grid cell of the dynamical model is divided into $N$ regularly spaced subgrid cells of equal area, each with its own specification of topographical elevation, vegetation class, and soil type. As input from the atmospheric model, BATS requires solar and infrared downward radiative fluxes, precipitation, and near-surface air temperature, water vapor, wind speed, pressure, and density. After the calculations of land surface processes are completed, BATS returns to the atmospheric model values for the albedo, surface upward infrared flux, momentum flux, sensible heat flux, and latent heat flux. Since the atmospheric model is run on the coarse grid and BATS on the fine subgrid, the atmospheric input to BATS needs to be disaggregated from the coarse grid to the subgrid. Similarly, the finescale SubBATS information needs to be reaggregated at the RegCM3 grid scale.

Based on G03, the model grid to subgrid atmospheric input disaggregation is only based on the coarse and fine-grid topographical information. In particular, in our standard setup, which is the same as in G03, we disaggregate surface air temperature according to the formula

$$
T_{i, j}^{\mathrm{sg}}=\bar{T}+\Gamma_{T}\left(\bar{h}-h_{i, j}^{\mathrm{sg}}\right)
$$

where the superscript sg refers to the subgrid and the overbar refers to the coarse grid, $T$ and $h$ denote the 
surface air temperature and topographical elevation, respectively, and $\Gamma_{T}$ is a mean atmospheric lapse rate, which we assume to be equal to $6.5^{\circ} \mathrm{C} \mathrm{km}^{-1}$ throughout the year (as in G03).

An important constraint for the disaggregation is that

$$
\bar{h}=\frac{1}{N} \sum_{i, j} h_{i, j}^{\mathrm{sg}}
$$

(i.e., that the coarse-grid elevation is equal to the mean of the subgrid elevations). With this assumption, Eq. (1) implies that the RegCM gridpoint air temperature is equal to the mean of the subgrid near-surface atmospheric temperatures. In other words, the integral of surface air temperature is preserved in the disaggregation process.

Following G03, surface pressure, density, and nearsurface air specific humidity are also disaggregated. Subgrid-scale surface pressure and density are calculated using the gas law based on the subgrid-scale temperature, while subgrid-scale near-surface air-specific humidity is computed assuming a constant near-surface relative humidity across subgrid points equal to the coarse-grid scale relative humidity. Also in this case the constraint is applied that the average of the subgridbox humidity is the same as the coarse-scale gridbox value. More detail on these disaggregation procedures can be found in G03.

Precipitation disaggregation is difficult because precipitation does not correlate simply either with topographical elevation or with land surface type, since topographical effects on precipitation depend on the direction of the wind with respect to the topographical slope, on wind speed, and on the topographical gradient. Thus, for the baseline experiment, no subgrid precipitation disaggregation is included. One sensitivity experiment is, however, conducted in which we disaggregate precipitation using an empirical formula to relate topography and precipitation. As mentioned earlier, different studies have found various dependencies of precipitation amounts on elevation depending on the specific context (Sasaki and Kurihara 2008). In our case we use the baseline simulation to construct an empirical curve relating precipitation to elevation and use this relationship to disaggregate precipitation based on the elevation differences between the model grid and the subgrid boxes. This procedure is explained in detail in section 4b. Near-surface wind and incoming radiative fluxes are currently not disaggregated.

Once the land surface calculations are computed at each subgrid box, surface momentum, energy (both sensible and radiative energy fluxes), and water fluxes need to be reaggregated at the model grid scale for input into the atmospheric component. Following G03, this is carried out by simple averaging over all subgrid boxes.

\section{c. Experiment design}

Figure 1 shows the model domain and topography used for the coarse dynamical model grid and the subgrid. The domain encompasses the Alpine region, the Italian Peninsula, and adjacent central Mediterranean regions. As mentioned, the coarse-gridcell size is $15 \mathrm{~km} \times 15 \mathrm{~km}$ on a Lambert Conformal projection (Fig. 1, top) while subgridcell size is $3 \mathrm{~km} \times 3 \mathrm{~km}$ (Fig. 1, bottom). Therefore, each coarse grid cell is divided into 25 subgrid cells. Note that the coarse-grid spacing of $15 \mathrm{~km}$ is currently considered as a state-of-the-art resolution for long-term regional climate model (RCM) simulations (Giorgi 2006). Both coarse-grid and subgrid topography represent the main topographical systems of the region; however, significant finer-scale detail is captured by the subgrid resolution, particularly over the Alpine region, where mountain peaks and valleys are more sharply defined. For example, only the subgrid topography captures mountain peaks higher than $2500 \mathrm{~m}$. Topographical information to obtain the two grids is taken from a 2-min resolution global dataset produced by the U.S. Geological Survey (USGS).

Figure 2 shows the land use distribution corresponding to the model domain of Fig. 1. Using the Global Land Cover Characterization (GLCC) dataset, we calculate the fractional cover of different surface types for each cell of the different model grids, and the grid cell is then assigned the surface type with the largest fractional cover among the 18 categories denoted by the legend in Fig. 2 . Comparison of the two land use distributions also shows that the spatial pattern of the $3-\mathrm{km}$ grid is much more detailed than that of the $15-\mathrm{km}$ grid.

Using this modeling system, we performed the series of experiments reported in Table 1. For model validation and for the evaluation of the effects of subgrid-scale heterogeneity, two simulations are integrated without and with implementation of the SubBATS scheme (CONT and SUB, respectively), without precipitation disaggregation, and with all other conditions being identical. One sensitivity experiment is carried out in which the lapse rate is increased from a mean value of $6.5 \mathrm{~K} \mathrm{~km}^{-1}$ to the adiabatic value of $9.8 \mathrm{~K} \mathrm{~km}^{-1}$ (SUB_LR: section 4a), thus allowing for a stronger dependency of temperature on elevation. Additionally, the other experiment is conducted with the elevation-dependent disaggregation of precipitation (SUB_H: section 4b) described above.

In all experiments, the initial and time-dependent lateral boundary conditions are interpolated at 6-hourly intervals from National Centers for Environmental Prediction/ Department of Energy (NCEP/DOE) Reanalysis II data (Kanamitsu et al. 2002). The SST over ocean areas is obtained from the National Oceanic and Atmospheric Administration (NOAA) Optimum Interpolation (OI) SST 

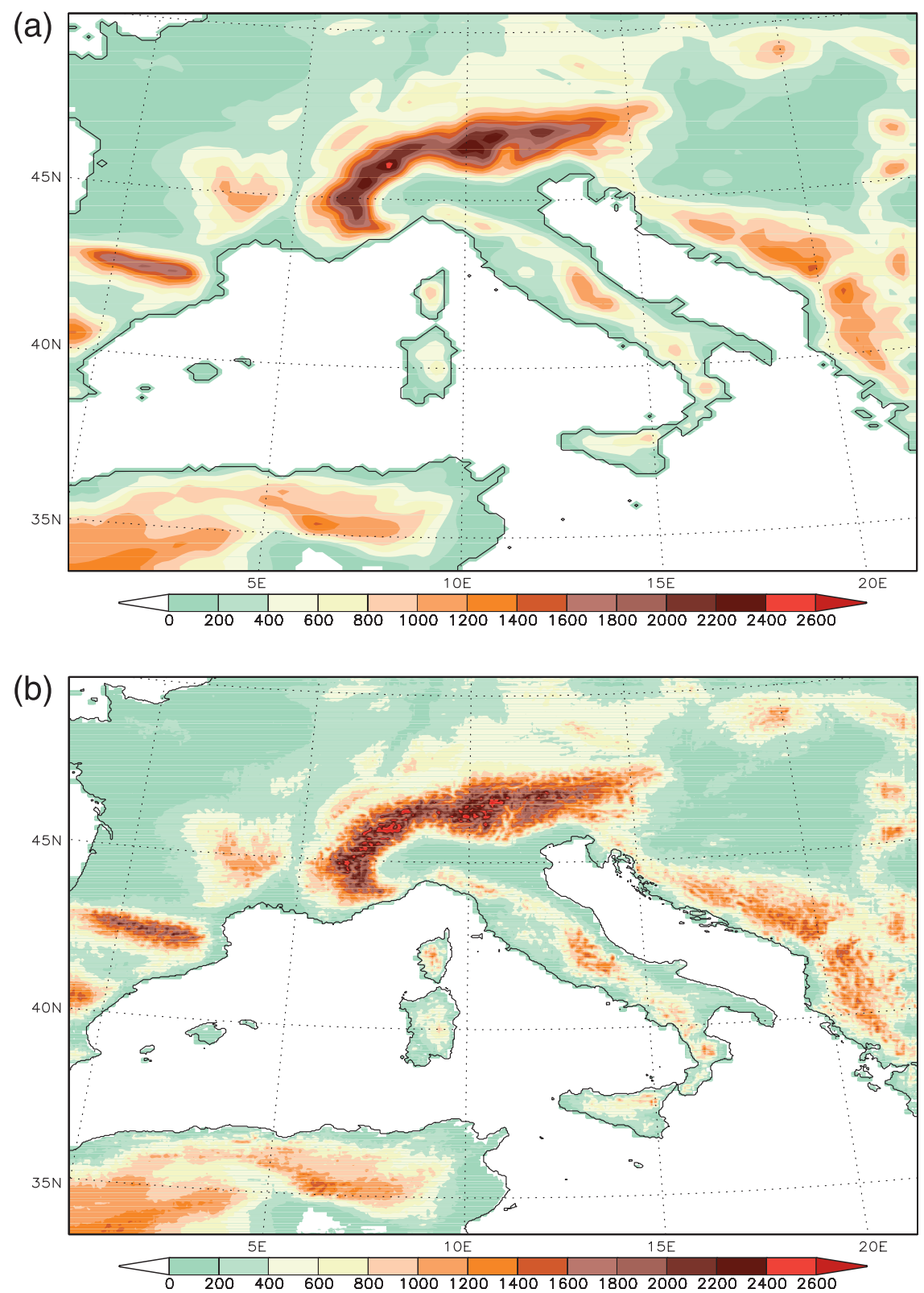

FIG. 1. Model domain and topography used for the (a) CONT and (b) SUB simulations. The model grid cells for the CONT and SUB experiments are 15 and $3 \mathrm{~km}$, respectively. Units for topography are $\mathrm{m}$.

dataset with a horizontal resolution of $1 \times 1$ at a weekly time interval. The CONT and SUB simulations span continuously the 10-yr (plus 4 months) period from 1 September 1982 through 31 December 1992, where the first 4 months of the simulations are not included in the analysis to allow for model spinup. The sensitivity experiments (SUB_LR and SUB_H) cover the 1-yr and 4-month period from 1 September 1982 through 31 December 1983, and again the first 4 months are not included in the analysis.

\section{d. Observational dataset}

Our analysis focuses on temperature, precipitation, and snow cover (i.e., variables significantly affected by the subgrid land surface representation; see G03). Two observational datasets are used for the evaluation of the simulations. For the whole domain we use a highresolution European land-only dataset of daily temperature and precipitation on a $25-\mathrm{km}$ grid (Haylock et al.2008). It has been shown that this dataset improves 

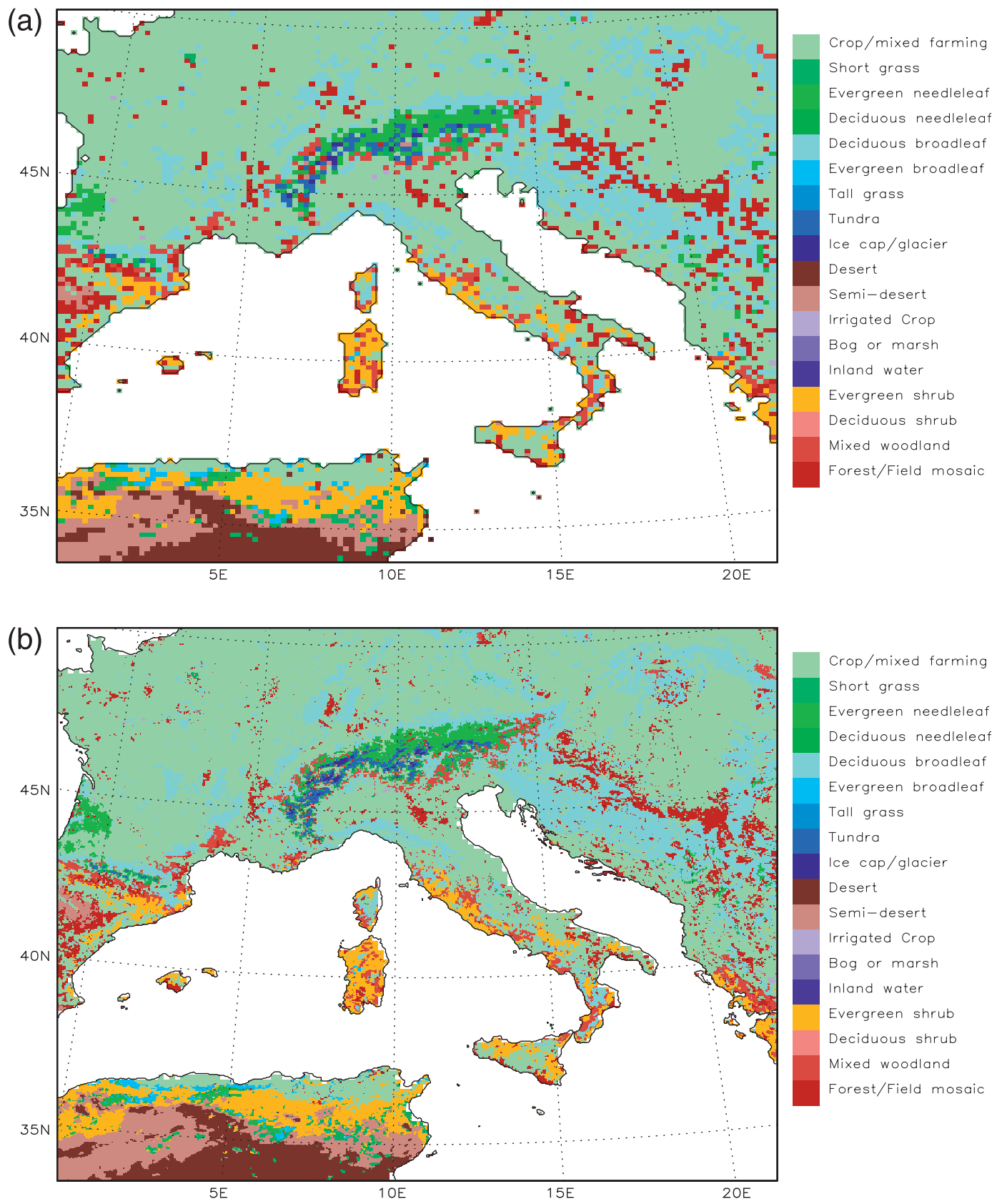

FIG. 2. Same as Fig. 1, but for land use distribution.

on previous products in several respects: spatial resolution and extent, temporal period covered, number of contributing stations, and method for spatial interpolation of daily climate data (Haylock et al. 2008). For more in-depth analysis of the local model performance over the Alpine region we also use a station dataset (STA) for Austria (133 stations) and Switzerland (25 stations) including precipitation and/or snow depth data (Fig. 3). Figure 4 shows a scatterplot of the altitudes of individual observational stations against the altitudes of model grid points closest to the station locations. A slope less than 1 indicates that the model topography is higher than the actual elevation of the observing stations. It can be seen that both the model grid and subgrid topographies mostly tend to overestimate the elevation compared to actual station heights, an indication of the well-known valley bias in station datasets ( $\mathrm{Wu}$ et al. 2005). However, the model topographies do not capture some very high elevation sites. It can also be seen that, although both model topographies are similarly biased 
TABLE 1. Experiment design used in this study.

\begin{tabular}{|c|c|c|c|}
\hline & Resolution & Period & \\
\hline CONT & $15 \mathrm{~km}$ & 1983-92 (10 yr) & Without SubBATS \\
\hline SUB & $3 \mathrm{~km}$ & $1983-92(10 \mathrm{yr})$ & With SubBATS \\
\hline SUB_LR & $3 \mathrm{~km}$ & $1983(1 \mathrm{yr})$ & $\begin{array}{c}\text { Sensitivity expt } \\
\text { of lapse rate }\end{array}$ \\
\hline SUB_H & $3 \mathrm{~km}$ & 1983 (1 yr) & $\begin{array}{c}\text { Sensitivity expt } \\
\text { of elevation } \\
\text { disaggregation }\end{array}$ \\
\hline
\end{tabular}

against observed elevations, an improved agreement is found for the subgrid case.

\section{Evaluation of the baseline simulation and effect of the subgrid scheme}

\section{a. Mean temperature and precipitation patterns over the whole domain}

We begin our analysis with the 10-yr climatology of the CONT simulation over the whole domain. Figure 5 shows the spatial distribution of the 10-yr average surface air temperature for the CONT simulation, the gridded observations, and their difference for the winter [December-February (DJF)] and summer [June-August (JJA)] seasons. Overall, the model results agree well with the observations, with biases being mostly less than $2^{\circ} \mathrm{C}$. The topographically induced spatial temperature distribution is well captured, although the model tends to underestimate temperature over some high-elevation areas of the Alps and Apennines. This discrepancy can at least partially be attributed to the relatively low density of high-elevation stations in the observed dataset, by which the data probably overestimate temperature in high mountain areas. The bias is lower in winter than in summer, where it is especially high over the Sahara Desert regions (in excess of $4^{\circ} \mathrm{C}$ in some regions). The tendency of the model to overestimate desert temperatures has been previously noted (Pal et al. 2007) and it likely depends on the specification of desert characteristics in the model (e.g., surface albedo). Being close to the southwestern corner of the domain, this error should not affect significantly our simulation in the target Alpine region.

Figure 6 shows mean JJA and DJF simulated and observed precipitation along with their difference. The model captures the topographically induced signature of the precipitation patterns, but overall it tends to overestimate precipitation, particularly over the mountainous areas and in the winter season. Also captured is the seasonal migration of precipitation, with wet winters and dry summers in the Mediterranean region. We note that the winter positive precipitation bias over the mountains may be artificially enhanced by the lack of a gauge undercatch correction in the observed data, which has been estimated to be up to $20 \%-30 \%$ (Adam and Lettenmaier 2003). In summer, the precipitation biases are smaller throughout the domain with values mostly less than a few $\mathrm{mm}_{\text {day }}{ }^{-1}$ (and less than $30 \%$ of observations). In general, the spatial patterns of precipitation are well reproduced, with correlation coefficients between observations and simulation of 0.65 in winter and 0.87 in summer (both

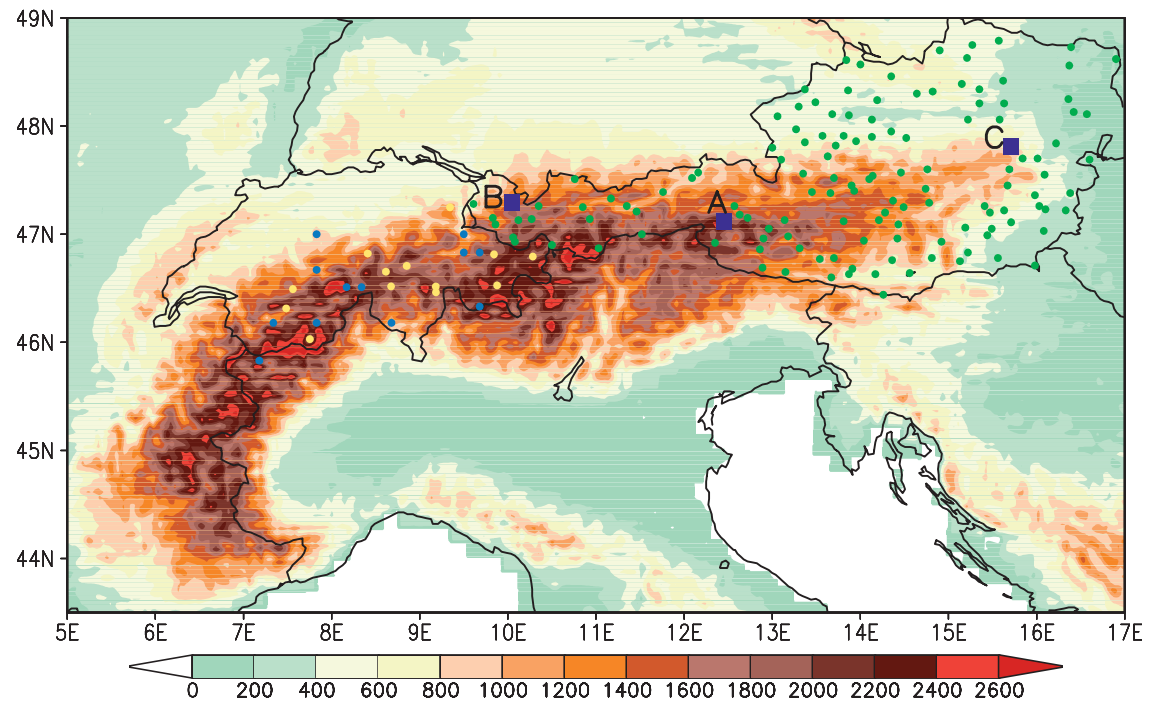

FIG. 3. Subdomain for the detailed analysis of precipitation and snow, and the locations of climate observational stations. Here, 133 green dots over Austria indicate stations with daily precipitation and snow depth data, while 13 yellow and 12 blue dots over Switzerland indicate stations with snow depth and precipitation data, respectively. The three squares indicated with $\mathrm{A}, \mathrm{B}$, and $\mathrm{C}$ are the locations of the three runoff stations at 1686, 943, and $602 \mathrm{~m}$, respectively. 

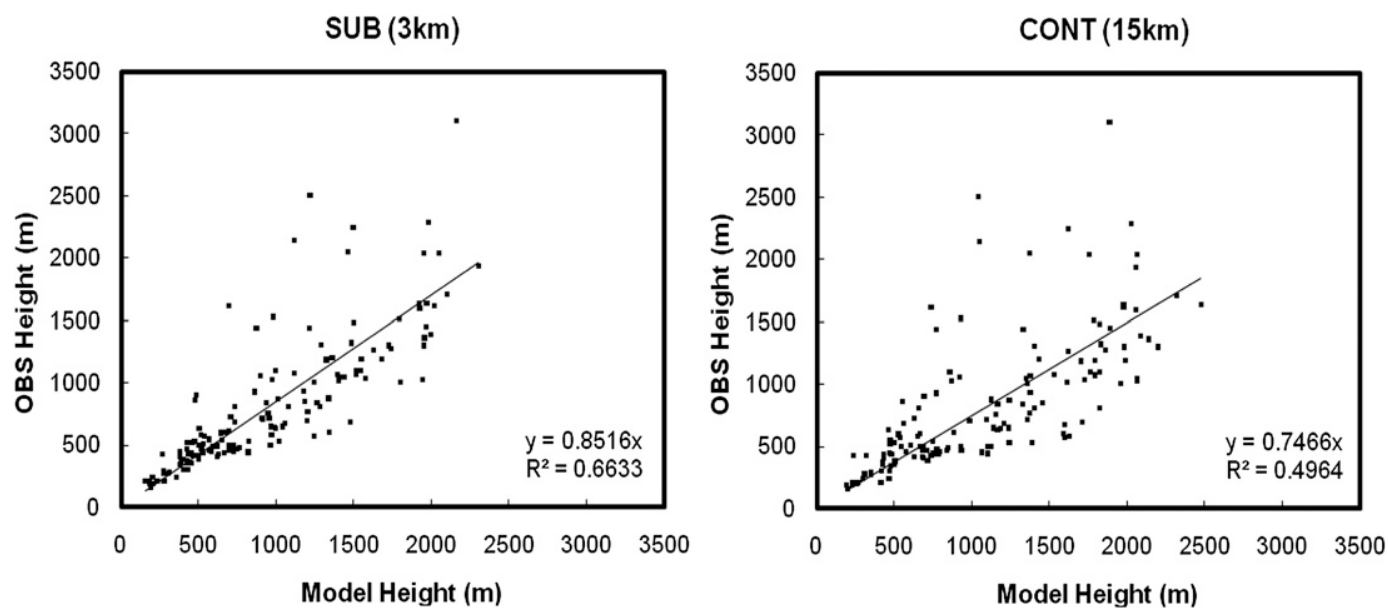

FIG. 4. Scatterplots of the altitudes of individual observational stations ( $y$ axis) against the altitudes of model grid points closest to the stations ( $x$ axis): (left) SUB and (right) CONT simulations.

coefficients are significant at the $95 \%$ confidence level). The correlation coefficients are calculated after the observations are aggregated onto the model grid $(15 \mathrm{~km})$ and including all the points in the interior domain. This is an encouraging performance, in particular showing some improvement compared to previous high-resolution RCM simulations over the region (e.g., Frei et al. 2003). Additional statistics are analyzed over the Alpine region in the following sections.

\section{b. Evaluation of the model and subgrid simulation over the Alps}

\section{1) TEMPERATURE AND PRECIPITATION}

Figure 7 shows the spatial distribution of seasonal mean temperature in the CONT and SUB simulations along with their differences. It is evident that the SUB simulation, although retaining the basic patterns of the CONT simulation (and thus the same bias patterns; see Fig. 5),

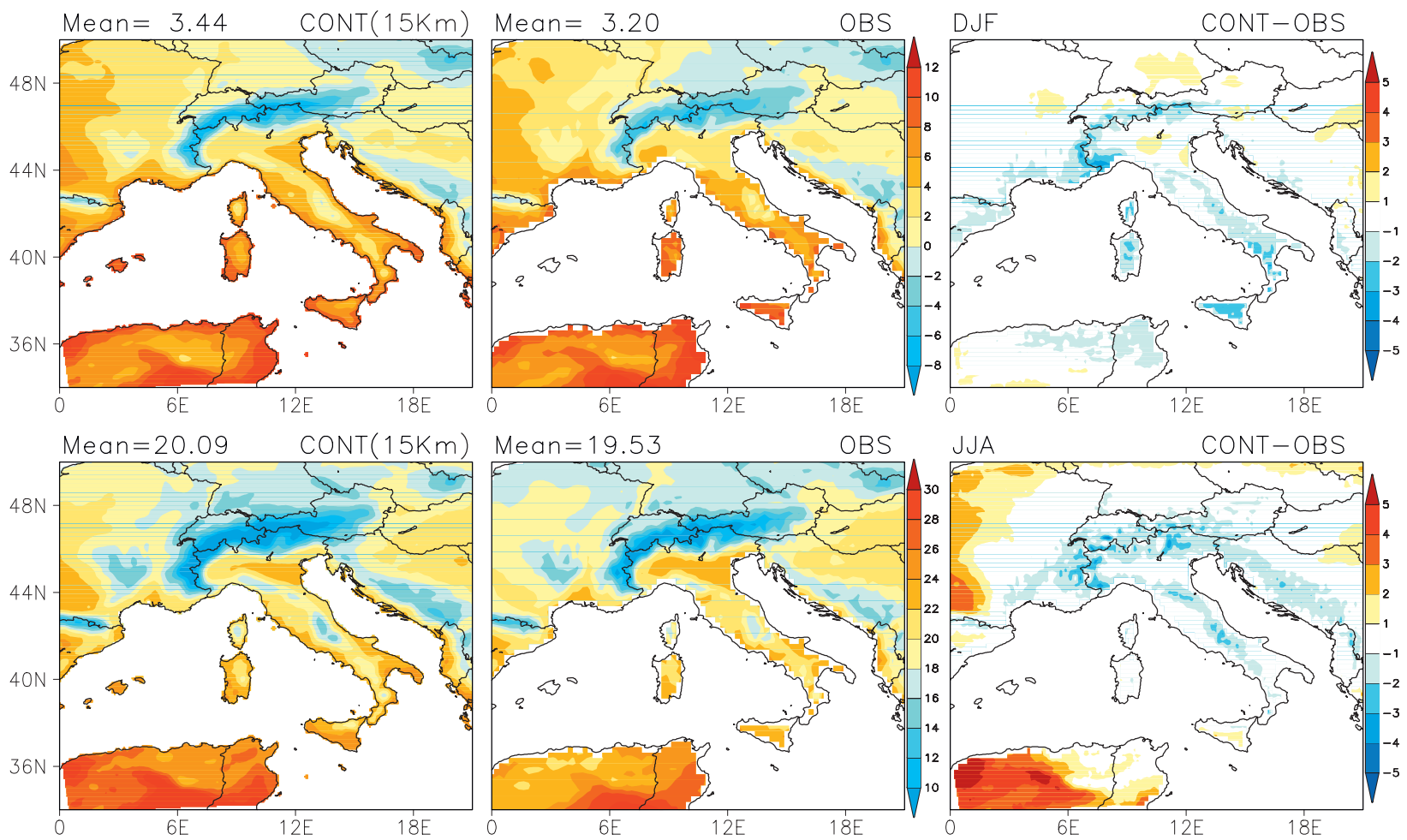

FIG. 5. Spatial distribution of seasonal mean (top) DJF and (bottom) JJA surface air temperature $\left({ }^{\circ} \mathrm{C}\right)$ over the whole domain. $($ left) CONT simulation, (middle) observations, and (right) their differences. 

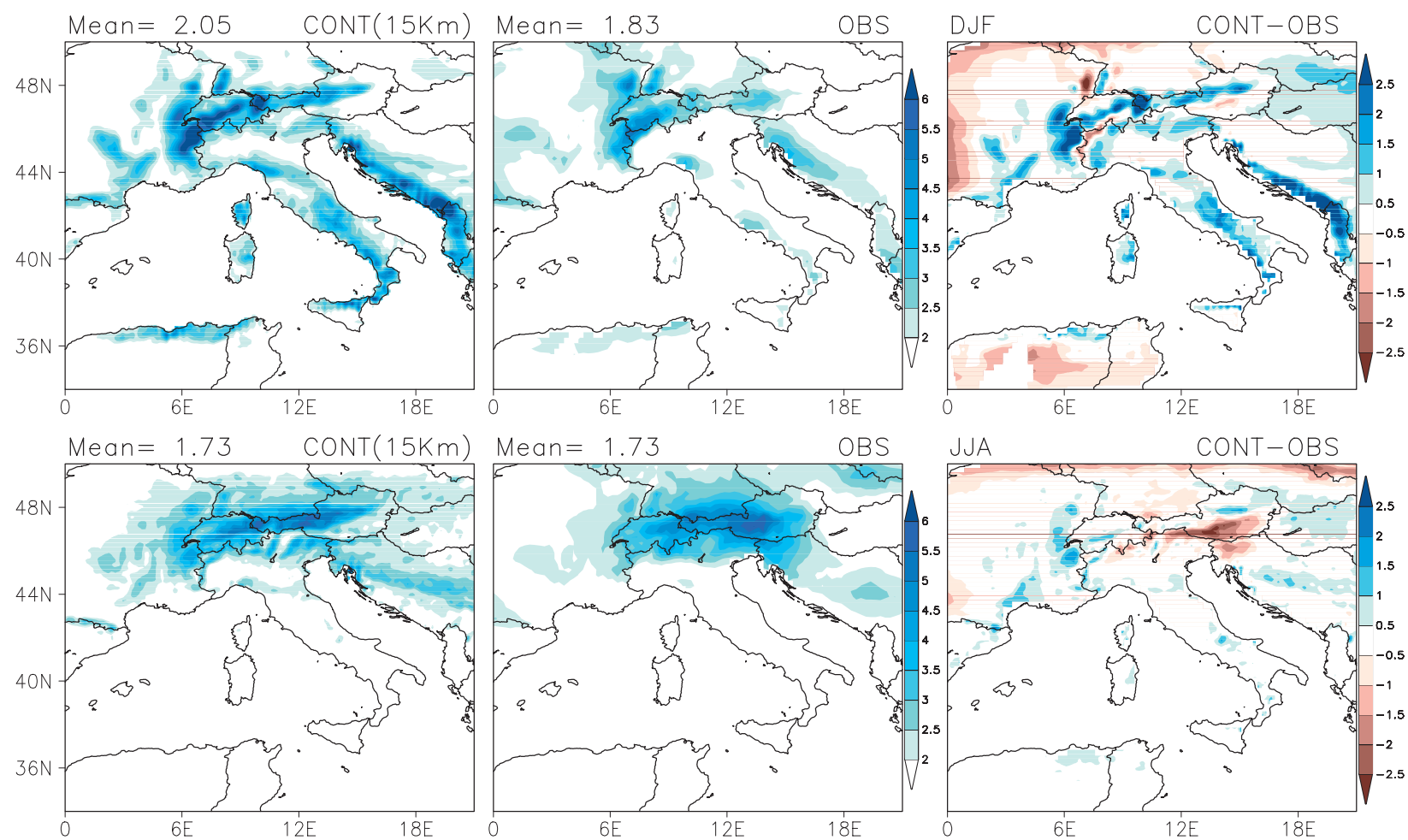

FIG. 6. Same as Fig. 5, but for seasonal average precipitation $\left(\mathrm{mm} \mathrm{day}^{-1}\right)$.

exhibits much finer resolution information. For example, peaks and valleys are much better resolved. The difference between the CONT and SUB temperature fields clearly indicates that the subgrid scheme mostly redistributes the grid-scale temperatures according to the fine and coarse topographical information without introducing systematic differences. Because precipitation is not disaggregated, essentially the CONT and SUB precipitation fields are very similar (see Fig. 6). In fact, differences between CONT and SUB precipitation are noisy and mostly attributable to the internal model variability (Giorgi and Bi 2000).

Figures $8 \mathrm{a}$ and $8 \mathrm{c}$ show the time series of monthly temperature and precipitation averaged for the entire Alpine region $\left(43.5^{\circ}-49^{\circ} \mathrm{N}, 5^{\circ}-17^{\circ} \mathrm{E}\right)$ shown in Fig. 7 in the CONT and SUB simulations along with observations. We first notice that the temporal evolution of the CONT and SUB simulations is essentially the same for both temperature and precipitation. In fact, the area averaging filters out the finescale spatial fluctuations of high and low values provided by the temperature distribution of the SUB simulation. Next, the observed and simulated (both SUB and CONT) temperature and precipitation time series show good phase coherence, as indicated by a high temporal correlation $(0.99$ and 0.85 , respectively), although the model tends to underestimate summer temperatures by up to about $1 \mathrm{~K}$. Alpine average precipitation is well reproduced, with biases mostly less than $1 \mathrm{~mm} \mathrm{day}^{-1}$.

Figure 8 also shows the scatter diagram of observed and simulated anomalies calculated as the monthly temperature (precipitation) minus the 10-yr average monthly temperature (precipitation), that is, after the annual cycle is removed. The $R^{2}$ value is derived by the linear regression between the observations and CONT simulation (the values from the SUB simulation are close to those for the CONT simulation). This plot thus provides information on the model accuracy in simulating the interannual variability on the monthly time scale. For the temperature anomaly, the slope and $R^{2}$ are close to one, implying a good model accuracy in reproducing monthly anomalies. For precipitation, the value of $R^{2}$ is still high (0.83) although a greater scatter of data is found. Also, the model-observation correlations for the mean annual cycle were 0.99 for temperature and 0.66 for precipitation. In the latter case, the relatively low value was due to the overestimate of winter precipitation in the model discussed above. Finally, the correlation between observed and simulated mean annual anomalies (which measure the interannual variability of annual values) is 0.99 for temperature and 0.79 for precipitation, again showing a good model performance.

Table 2 reports the spatial correlation and bias between the simulations (CONT and SUB) and observations 

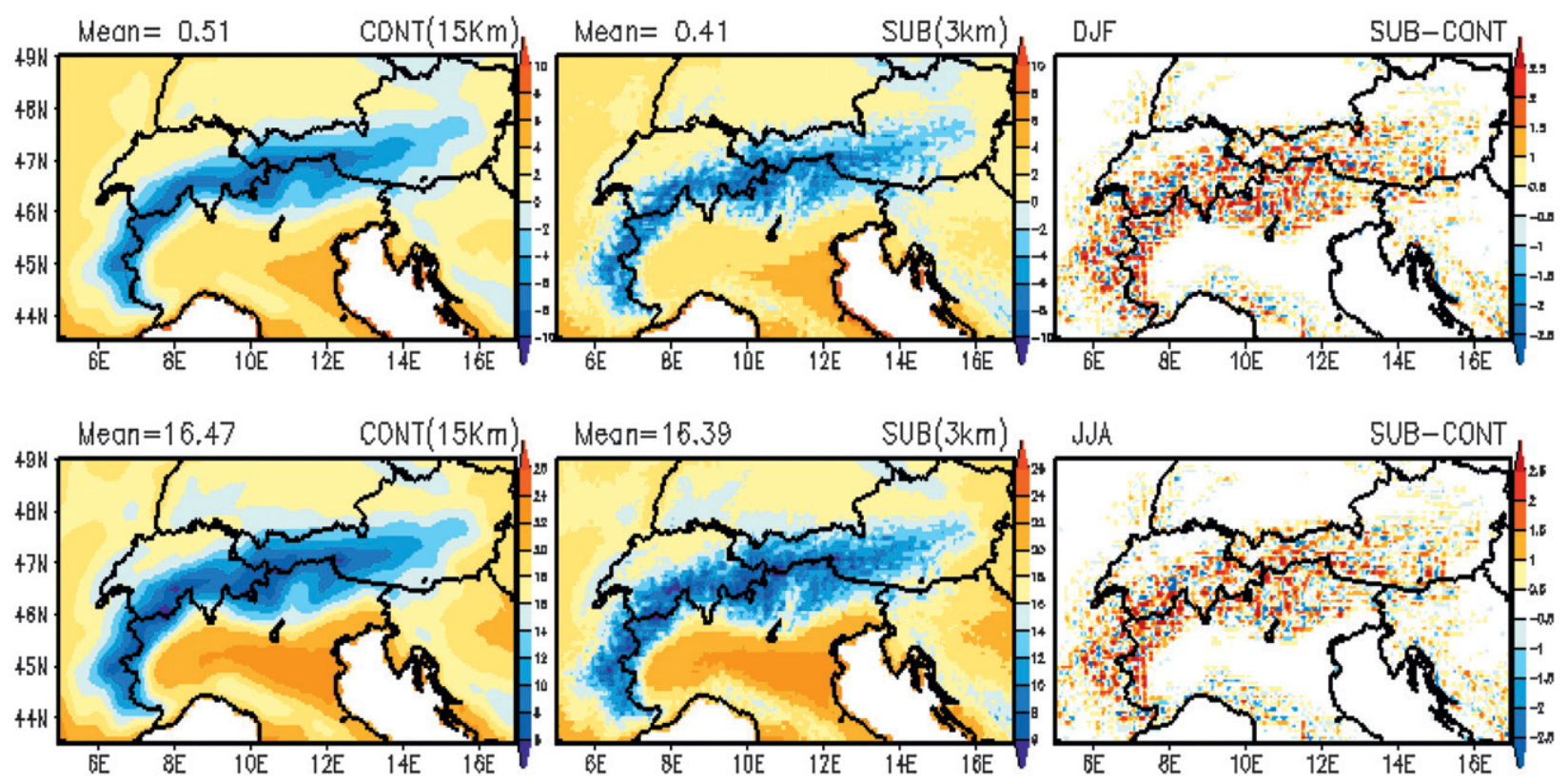

FIG. 7. As in Fig. 5, but for the Alps subdomain: (left) CONT simulation, (middle) SUB simulation, and (right) their differences.

(Table 2). The pattern correlation measures the agreement between the spatial patterns of simulated and observed data while the bias is a direct measure of how the model average climatology deviates from that observed. Here, we calculate the pattern correlation coefficient after interpolating the model output data to the 25-km observation grid.

For temperature, the model generally shows a slight cold bias except for winter, with magnitude less than $1^{\circ} \mathrm{C}$. Temperatures in the SUB simulation are about $0.1^{\circ} \mathrm{C}$ lower than in CONT. The pattern correlation coefficients are high, greater than 0.9 , as a result of the strong topographical forcing. Precipitation biases for DJF and March-May (MAM) are positive and reach up to $20 \%$ while biases for JJA and September-November (SON) are less than $10 \%$ and mostly negative. As mentioned, the positive precipitation biases in winter and spring might be artificially enhanced by the lack of a gauge correction in the observations, which is especially important during snow events. The precipitation pattern correlation coefficients are also high, varying between 0.58 and 0.77 . We note that this performance is generally superior to that of various regional climate model simulations with a grid spacing of $50 \mathrm{~km}$ for the European Alps reported by Frei et al. (2003). We also note that when upscaling to the $25-\mathrm{km}$ scale, the effect of the subgrid scheme is very small.

Daily statistics are critical for the application of climate information to impact studies. Figures 9 and 10 show the frequency distribution of daily temperature and precipitation over the Alps subdomain in the winter and summer seasons for the CONT and SUB simulations and the gridded and station (precipitation only) observation datasets. Note that the distributions are normalized by the number of daily events, which is different for the simulations and observations because of their different resolutions. We pooled daily temperature and precipitation for all grid points and stations included in the Alpine subdomain [52056 for the 3-km resolution SUB; 2064 for the 15-km resolution CONT; 964 for the $25-\mathrm{km}$ gridded observation (OBS): 145 for the precipitation station dataset STA] and calculated the relative percentile, dividing by the total number of events in the samples contributing to the distribution. For the precipitation frequency versus intensity distribution, we define a precipitation event as a daily precipitation value greater than or equal to $1.0 \mathrm{~mm}$.

Considering temperature first (Fig. 9), the model reproduces extremely well the observed daily probability distribution function (PDF) in winter, in terms of both mean and variance. In summer the simulated PDF is shifted toward lower values as a result of the cold bias (less than $1^{\circ}$ ) mentioned earlier. The simulated PDF is also slightly narrower, indicating a lower variance, although the tails are captured. To diagnose the temperature error dependence on elevation we separately calculated the frequency distribution of daily temperature for three elevation ranges (0-500, 500-1500, and over $1500 \mathrm{~m}$; not shown). During summer, the frequency distribution for low elevations $(0-500 \mathrm{~m})$ was closer to the observed one than that in Fig. 9, while the shift toward a colder mean value was worse for high levels (over $1500 \mathrm{~m}$ ). This implies that 
(a)

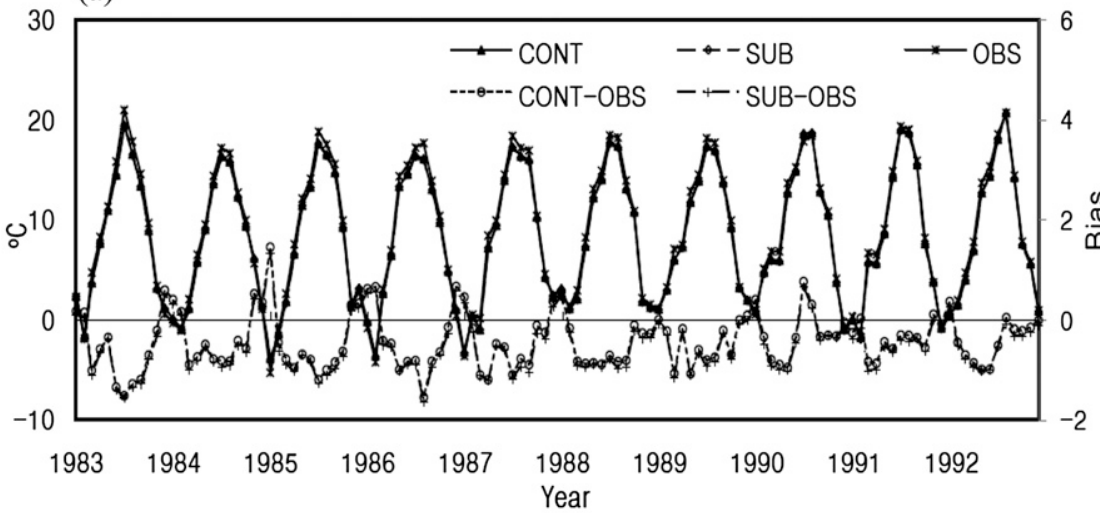

(c)

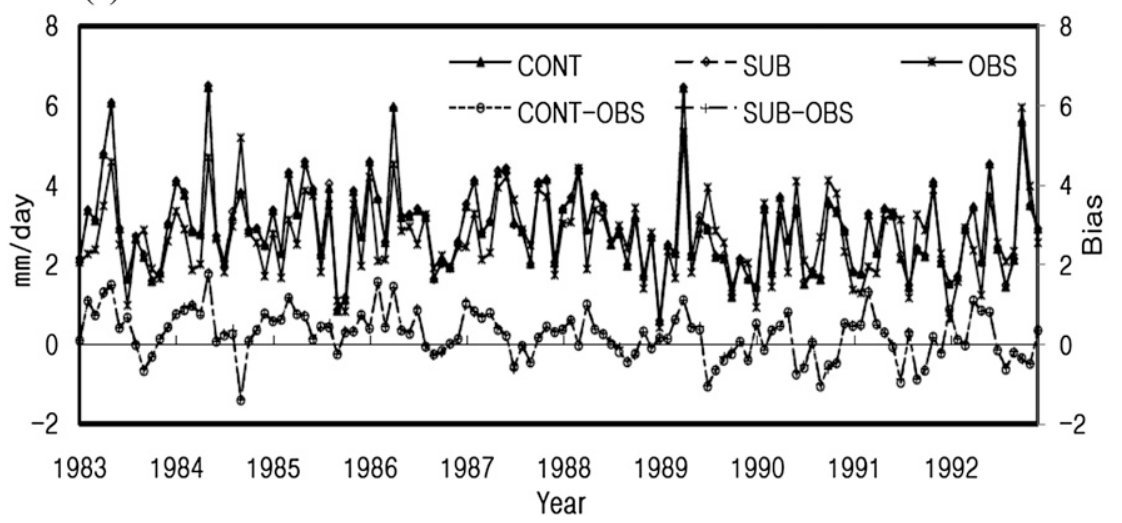

(b)

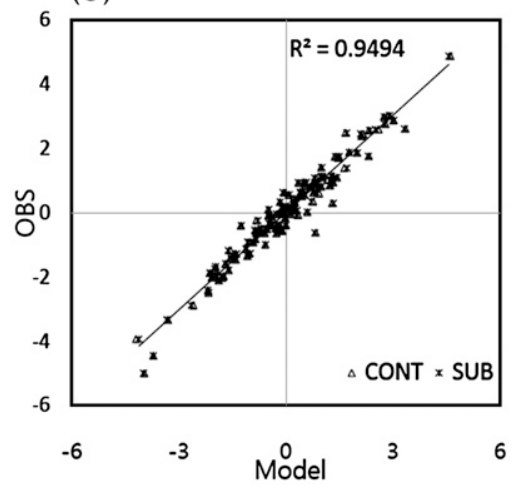

(d)

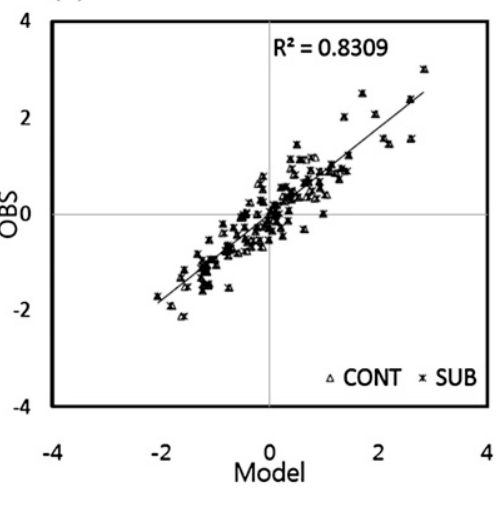

FIG. 8. Time series of monthly averaged (a) temperature and (c) precipitation for the CONT and SUB simulations and observations along with their biases over the Alps subdomain. Scatter diagrams of observed and simulated (b) temperature and (d) precipitation anomalies when the mean seasonal cycle is removed.

the differences between simulated and observed summer PDFs are mostly due to high-elevation observing sites.

When examining the overall daily temperature distributions (Figs. 9a,b), we do not find large differences between the CONT and SUB simulations because of the compensating effects of points with higher and lower elevations. However, when we closely examine the tails of the distribution (Figs. 9c,d refer to the left tail, and similar conclusions are found for the right one) we find that the subgrid scheme produces higher frequencies. In particular, some temperatures present in the SUB sim- ulation are not found in the CONT one (difference of $-100 \%$ in the figure). This is because of the wider elevation ranges present in the subgrid topographical field. Therefore, while the subgrid scheme does not affect the bulk of the temperature PDF, it can affect its tails.

Figure 10 shows the distribution of daily precipitation frequency versus intensity for the winter and summer seasons. For relatively low intensities, below $50 \mathrm{~mm}^{\text {day }}{ }^{-1}$, the simulated distributions match the observed gridded one reasonably well. However, the model tends to overestimate frequencies in the middle- and high-intensity

TABLE 2. Bias and spatial pattern correlation coefficient of seasonal mean temperature and precipitation over Alps.

\begin{tabular}{|c|c|c|c|c|c|c|}
\hline & & & DJF & MAM & JJA & SON \\
\hline \multirow[t]{4}{*}{ Temperature } & $\operatorname{Bias}\left({ }^{\circ}\right)$ & CONT & 0.18 & -0.78 & -0.72 & -0.36 \\
\hline & & SUB & 0.08 & -0.85 & -0.79 & -0.46 \\
\hline & P-Corr & CONT & 0.94 & 0.98 & 0.98 & 0.96 \\
\hline & & SUB & 0.91 & 0.97 & 0.96 & 0.94 \\
\hline \multirow[t]{4}{*}{ Precipitation } & $\operatorname{Bias}\left(\mathrm{mm} \mathrm{day}^{-1}\right)(\%)$ & CONT & $0.47(20.6)$ & $0.76(20.0)$ & $-0.0(-0.03)$ & $-0.24(-8.32)$ \\
\hline & & SUB & $0.47(20.6)$ & $0.77(20.1)$ & $0.04(1.3)$ & $-0.23(-8.19)$ \\
\hline & P-Corr & CONT & 0.69 & 0.72 & 0.77 & 0.60 \\
\hline & & SUB & 0.67 & 0.71 & 0.75 & 0.58 \\
\hline
\end{tabular}


(a) Temp. [DJF]

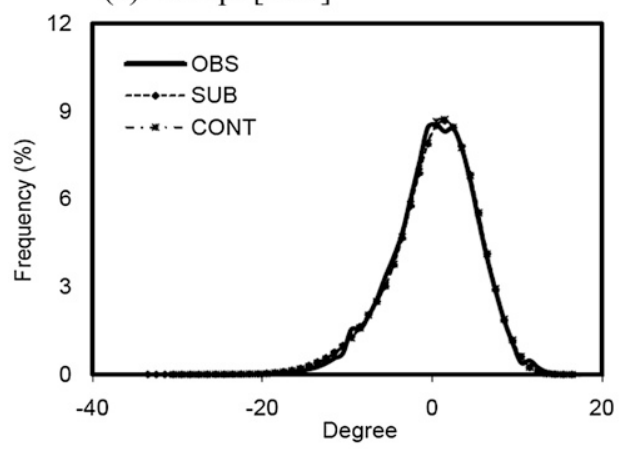

(c) Temp. [DJF]

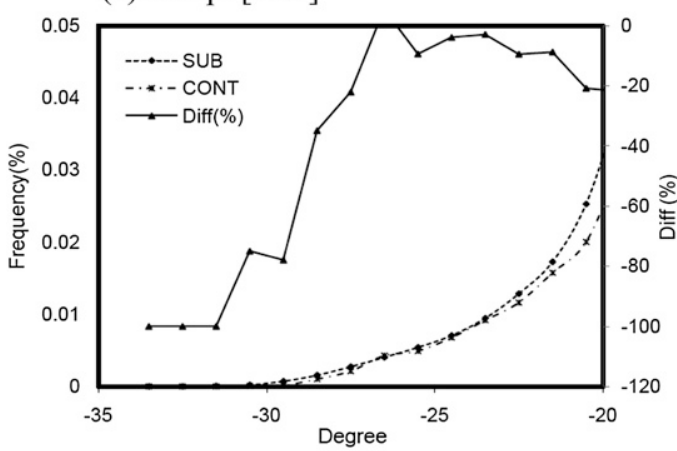

(b) Temp. [JJA]

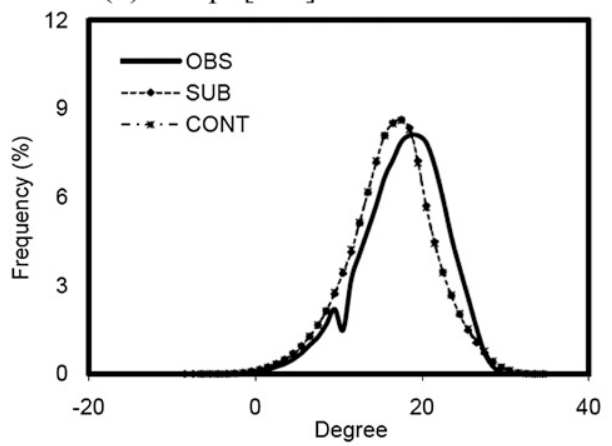

(d) Temp. [JJA]

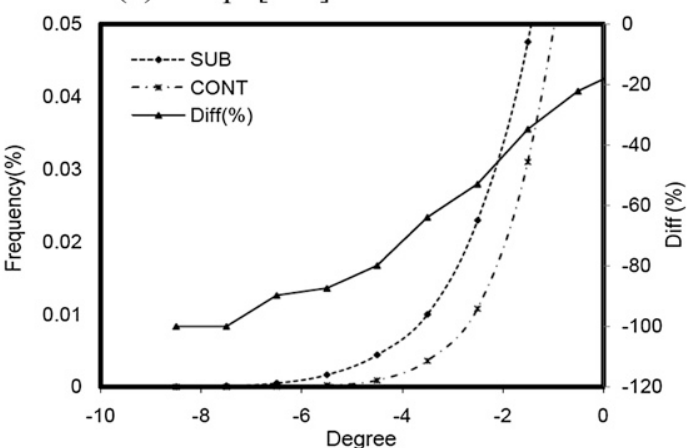

FIG. 9. Frequency distribution of daily temperature over the Alps subdomain for the (a),(c) winter and (b),(d) summer seasons in the CONT and SUB simulations and their differences.

range. The degree of mismatch between the gridded observations and the simulations is amplified as the intensity increases. This may be due to the coarser resolution of the gridded observations compared to the model. To verify this hypothesis, we added to Fig. 10 the precipitation distribution from 145 stations (Austria: 133 plus Switzerland: 12; see Fig. 3). Indeed, the station data show substantially higher frequencies of high-intensity events, which lead to a better agreement with the simulated PDFs. We thus conclude that the gridding process might affect the observed frequencies in the gridded observation dataset.

\section{2) SNOW AND THE HYDROLOGIC BUDGET}

Snow is one of the most important aspects of the hydrologic cycle of mountainous regions and, as shown by G03, can be affected by the subgrid topographic forcing. Figure 11 shows the spatial distribution of the seasonally averaged snow depth for the winter, spring, and summer (a) Precip. [DJF]

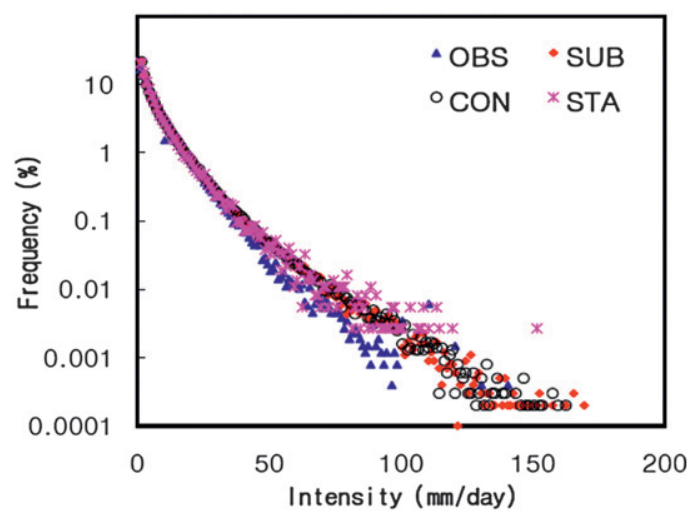

(b) Precip. [JJA]

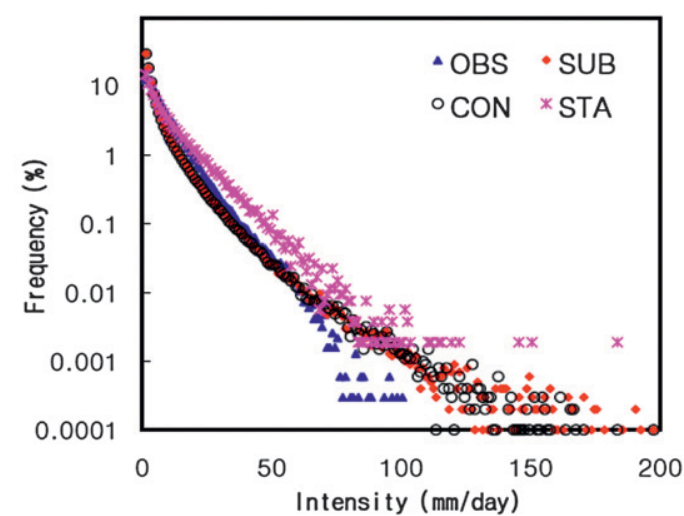

FIG. 10. Frequency distribution of daily precipitation over the Alps subdomain for the (a) winter and (b) summer seasons in the CONT and SUB simulations and the gridded (OBS) and station (STA) observations. 

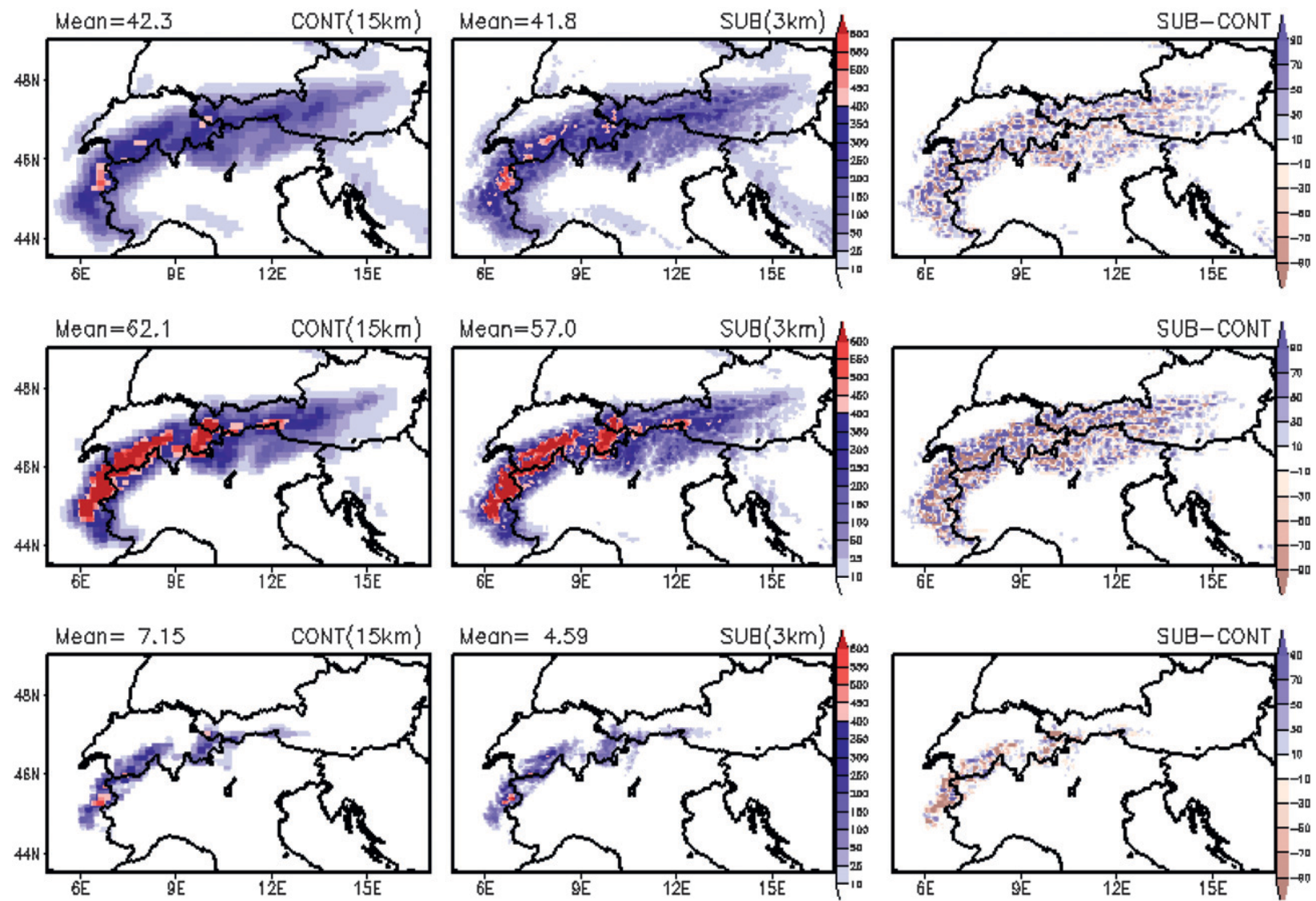

FIG. 11. Spatial distribution of seasonal averaged snow depth (top) DJF, (middle) MAM, and (bottom) JJA over the Alps subdomain. (left) CONT simulation, (middle) SUB simulation, and (right) their differences. Units are equivalent mm of water.

seasons in the CONT and SUB simulations on the respective surface grids. Although precipitation is similar in the two simulations, the SUB run shows a much more refined distribution of snow that follows the subgrid topography. This is because of the elevation-based tem- perature disaggregation. In BATS, if the surface air temperature is lower than $273.16^{\circ} \mathrm{C}$, precipitation is in the form of snow. Hence, precipitation can be in the form of snow over the higher subgrid peaks and rain over the subgrid valleys. Indeed, both in winter and spring the

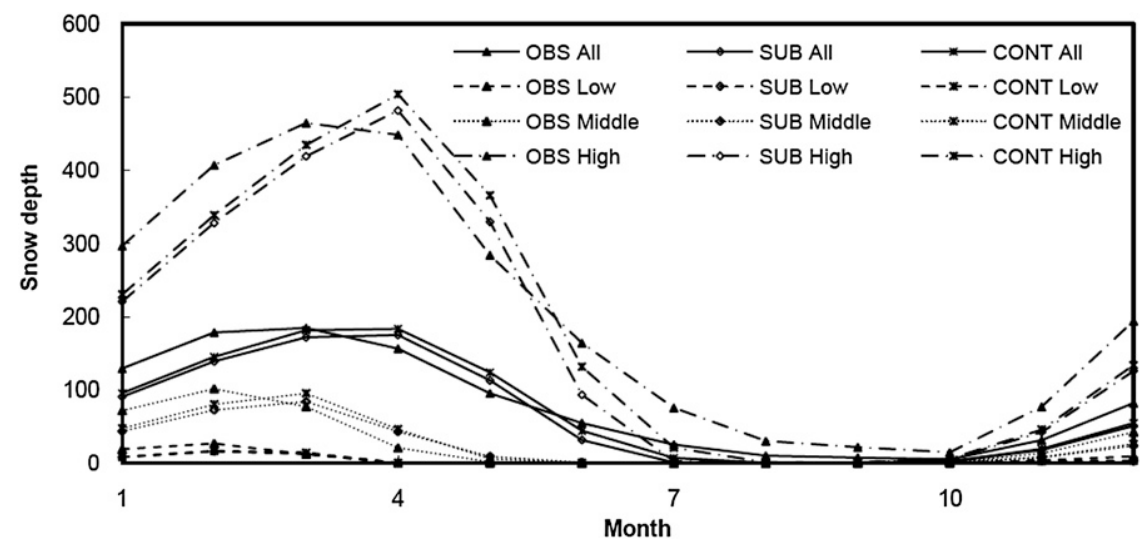

FIG. 12. Monthly variation of snow depth averaged over the Alps subdomain. Low, middle, and high levels indicate $0 \mathrm{~m}<h<500 \mathrm{~m}, 500 \mathrm{~m} \leq h<1500 \mathrm{~m}$, and $h \geq 1500 \mathrm{~m}$, respectively. Units are equivalent $\mathrm{mm}$ of water. 

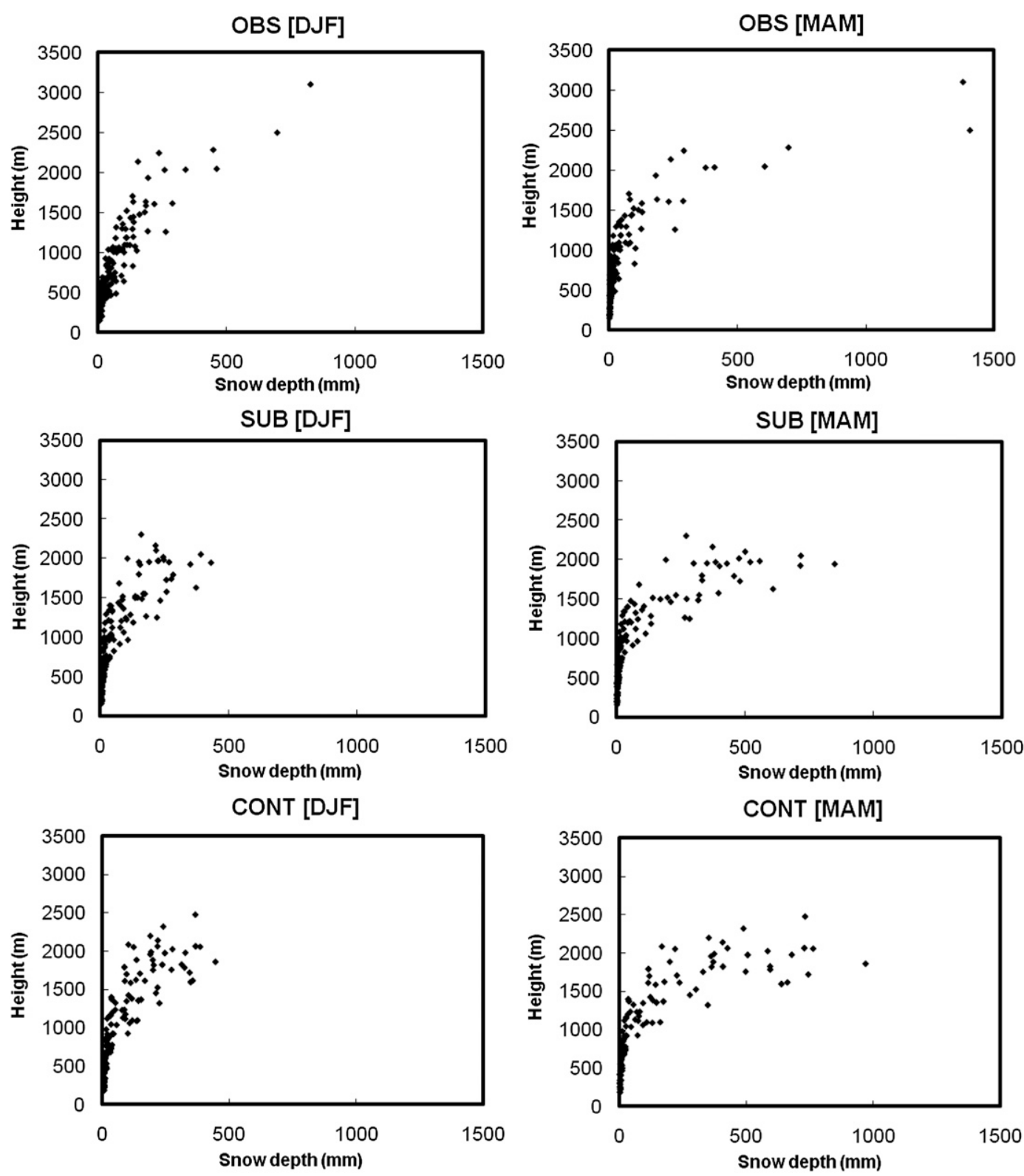

FIG. 13. Scatterplots of the altitudes of 146 individual stations ( $y$ axis) against snow depth at the corresponding locations ( $x$ axis) for the (left) winter and (right) spring: (top) observations, (middle) SUB simulation, and (bottom) CONT simulation.

snow distribution follows the finescale geographical distribution of the major Alpine valleys and ridges.

Regarding the seasonal variation of snow depth, during winter snow shows a more widespread distribution but lower amounts compared to the spring. Maximum localized snow depths over high mountain ridges are found in spring resulting from snow accumulation, which is in good agreement with the seasonal behavior of observed snow over the Alps (see also G03). During summer snow mostly disappears, but the model still produces snow depths over the highest peaks, a result also in line with observations (G03). Comparing the total snow depths in the CONT and SUB simulations, we find that, when averaged over the whole Alpine region, CONT produces higher amounts. Two competing processes contribute to the differences between CONT and SUB snow depths: greater (lower) snow depths will be maintained in SUB over areas where the elevation is higher (lower) than in CONT. Therefore, in our simulations the lowelevation melting contributes to a greater extent than the high-elevation cooling, so that averaged snow depths are greater in CONT. 
(a) Precipitation

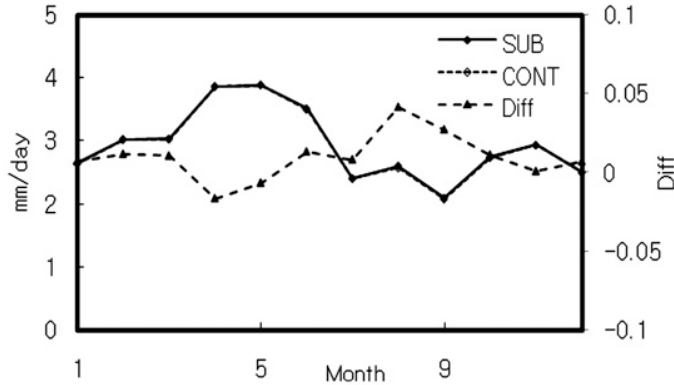

(c) Snow water equivalent

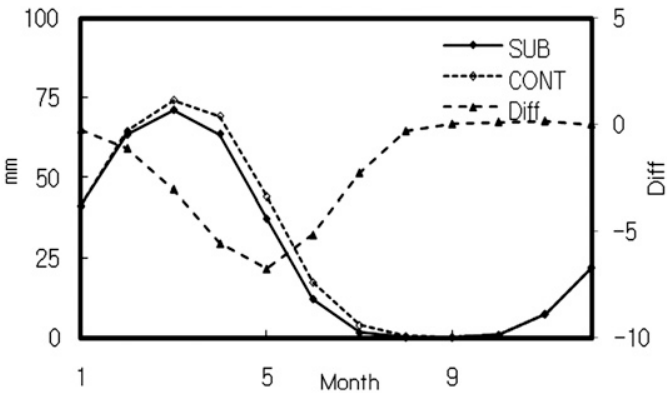

(e) Root layer soil moisture

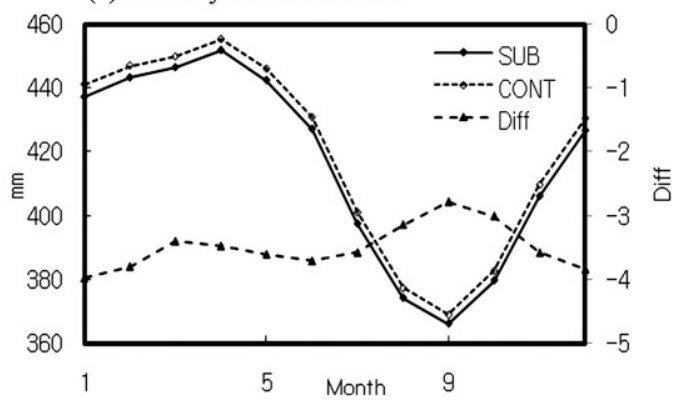

For an assessment of the snow simulation, we compare the monthly variation of snow depth from the CONT and SUB simulations with observations based on the 146 stations over the Alps subdomain (Fig. 12). The model grid points closest to the station location are used in the comparison. Also, since the model snow is described in terms of equivalent water depth and the observations in centimeters of snow depth, the two quantities need to be rescaled to the same units. Following G03, we thus scale the observed snow depth by a factor of $1 / 3$, which is roughly characteristic of the density of aging snow, to obtain the equivalent liquid water depth (e.g., Dickinson et al. 1993). Note that this assumption is highly uncertain, as the scaling factor can have a wide range of values depending on the density and age of snow, thus the comparison with observations is necessarily limited in scope and mostly aims at providing semiquantitative indications of the model behavior. To assess the elevation dependence of snow simulation, we analyze not only the all-station averages but also three elevation ranges- (b) Evapotranspiration

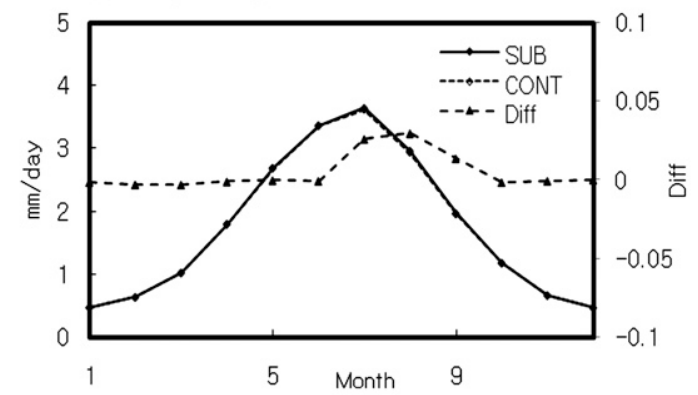

(d) Surface runoff

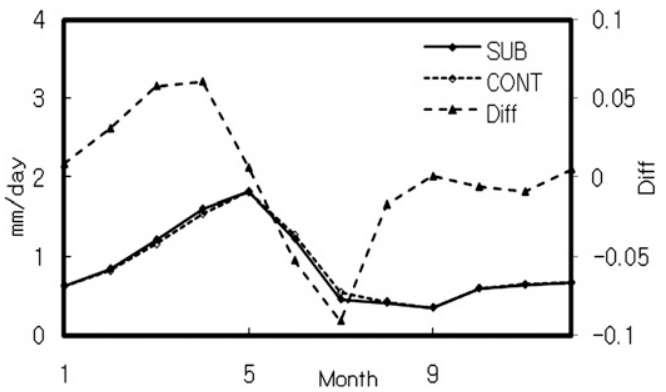

FIG. 14. Monthly variation of area-averaged (a) precipitation, (b) evapotranspiration, (c) snow water equivalent, (d) surface runoff, and (e) root layer soil moisture over the Alps subdomain and corresponding difference between the SUB and CONT simulations.

low level: $0 \mathrm{~m}<$ height $<500 \mathrm{~m}$, midlevel: $500 \mathrm{~m} \leq$ height $<1500 \mathrm{~m}$, and high level: height $\geq 1500 \mathrm{~m}$.

In the observations we see two features. First, the snow depths increase sharply with elevation and, second, the peak snow cover occurs later in time as the elevation increases, from February at low-elevation sites to March at mid- and high-elevation sites. Highelevation observing sites also show a small amount of snow cover in the summer months. In the simulations we also find a sharp increase in snow cover with elevation in line with observations. The seasonal cycle of snow cover, however, shows differences compared to the observing stations. Snow cover appears to be underestimated in the winter months and overestimated in the late spring ones, which results in a late occurrence of the peak snow month compared to observations (February, March, and April at low, mid-, and high elevations, respectively). In addition, the model produces negligible snow cover during the midsummer months at the station locations examined. 
The model-observation discrepancies can be attributed, at least partially, to the height differences seen in Fig. 4. The number of station sites included in the highlevel category (height $\geq 1500 \mathrm{~m}$ ) is different for observations and simulations (OBS: 17, SUB: 26, CONT: 39 stations), and the elevations used in the simulations at the station sites are overall higher than the actual ones. This might contribute to the displacement of the peak snow cover month. On the other hand, very high elevations above $2500 \mathrm{~m}$ do not occur in the model topography (Fig. 4) and the observed snow amounts lasting throughout the summer season are due to two stations with extremely high elevation (2502 and $3105 \mathrm{~m})$. Another parameter that might influence the observation-model peak snow month discrepancies is the use of a constant conversion factor from equivalent water depth to snow depth. Since this factor varies with snow age, it is likely to also have a seasonal dependence, with snow being more compact in spring than winter. The conversion factor would thus be smaller in winter than spring and this would decrease the observed values of Fig. 12 in winter and increase them in spring. This would in turn improve the agreement with observations.

Consistently with the discussion above, the comparison of the snow depths in the CONT and SUB cases shows larger depths in the former case. This appears to occur particularly in the snowmelt months (i.e., snowmelt occurs more rapidly in the SUB simulation where the distribution of snow is more heterogeneous). Figure 13 shows the dependency of snow depths on elevation for observations and the two simulations in winter and spring. Both in the models and observations, the snow depth increases sharply with height, with this dependency being more pronounced in winter than spring. In winter there are more stations with low snow amounts and fewer stations with very large amounts. Two very high-elevation snow cover stations are found in the observed dataset that are not present in the model. It also appears that the model underestimates the number of low-snow depth sites in winter.

Overall, although the subgrid scheme provides more refined and seemingly more realistic snow patterns following the enhanced topographic representation, it is difficult to assess whether in an averaged sense the reduced snow depths in the subgrid scheme are more realistic. This would require a much more dense station network including both low- and high-elevation sites.

To investigate the SubBATS effect on the hydrologic cycle, we present in Fig. 14 the monthly variation of water budget components area averaged over the Alps subdomain from the SUB and CONT simulations along with their differences. As expected, snow exhibits the most significant seasonal variation and pronounced dif- (a)

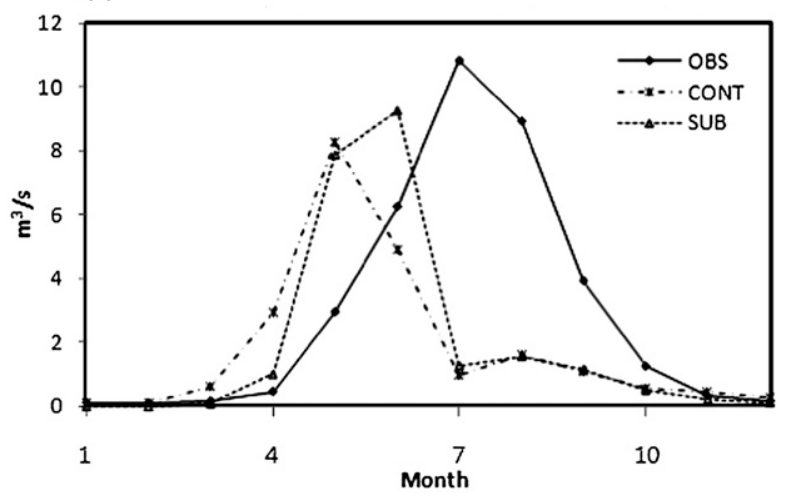

(b)

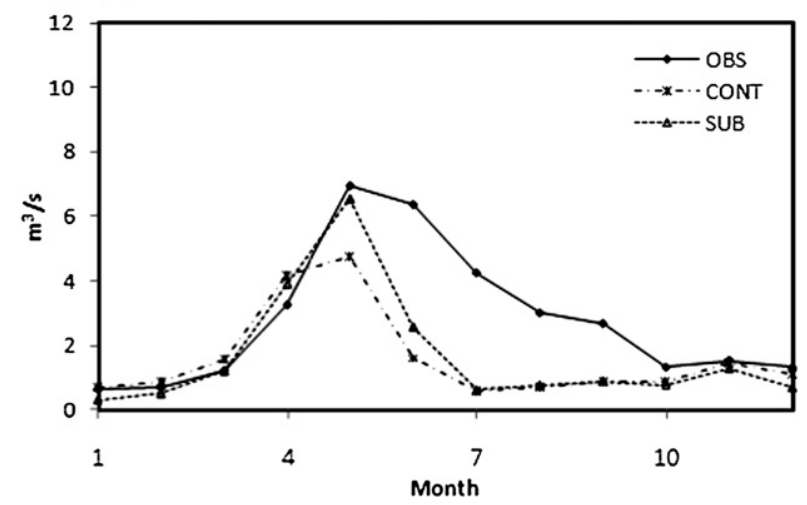

(c)

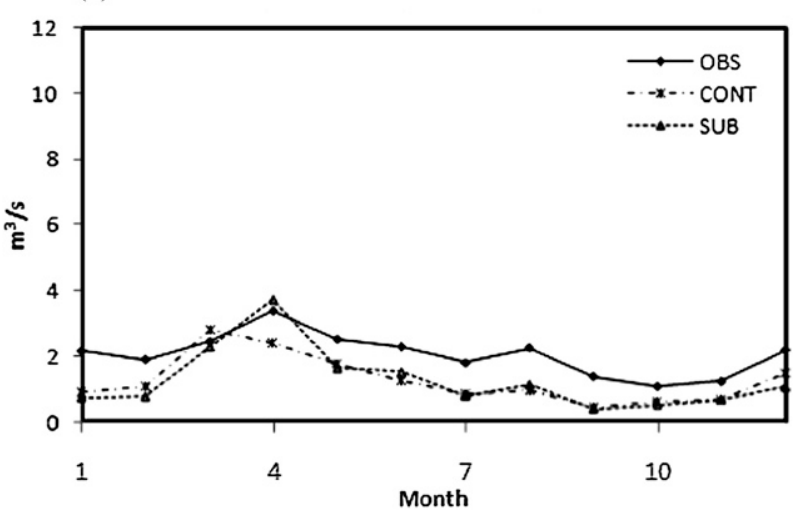

FIG. 15. Monthly variation of runoff (10-yr average) from observations and the CONT and SUB simulations at three observed sites over Austria: (a) $1686 \mathrm{~m}, 47.13^{\circ} \mathrm{N}, 12.47^{\circ} \mathrm{E}$, (b) $943 \mathrm{~m}$, $47.29^{\circ} \mathrm{N}, 10.05^{\circ} \mathrm{E}$, and (c) $602 \mathrm{~m}, 47.82^{\circ} \mathrm{N}, 15.69^{\circ} \mathrm{E}$.

ference between the SUB and CONT simulations compared to the other hydrologic components (Fig. 14c). Consistent with the previous analysis, the SUB experiment mostly produces less snow, and the difference with respect to the CONT simulation is at a maximum during the snow melting period. The snow melting difference is reflected as well in the difference in runoff (Fig. 14d), which also has a maximum in the summer season, with the CONT simulation producing more runoff than the 

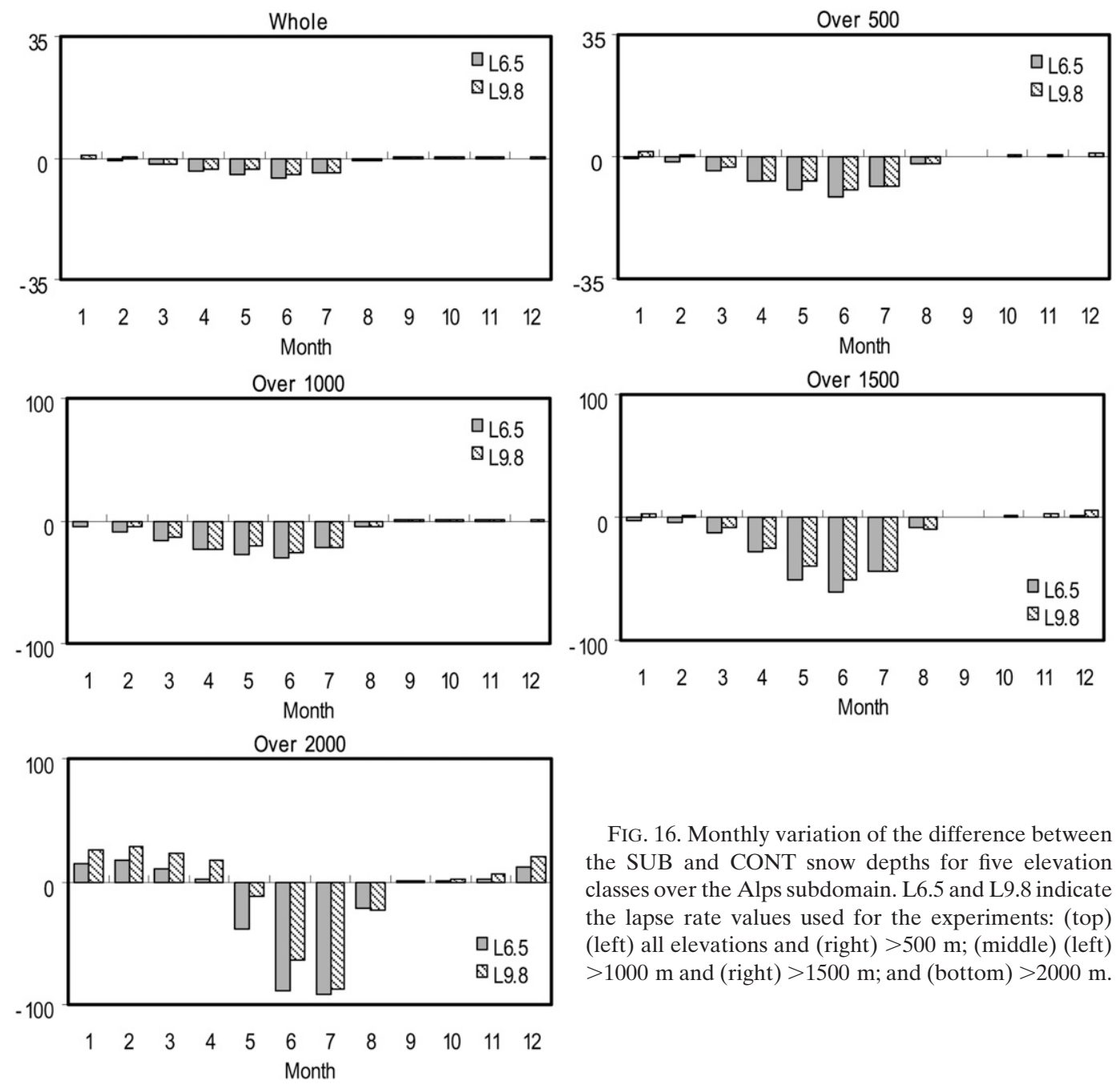

FIG. 16. Monthly variation of the difference between the SUB and CONT snow depths for five elevation classes over the Alps subdomain. L6.5 and L9.8 indicate the lapse rate values used for the experiments: (top) (left) all elevations and (right) $>500 \mathrm{~m}$; (middle) (left) $>1000 \mathrm{~m}$ and (right) $>1500 \mathrm{~m}$; and (bottom) $>2000 \mathrm{~m}$.

SUB one. Differences in precipitation and evapotranspiration between SUB and CONT are small.

All the plots in Fig. 14 are area averaged over the whole Alpine region $\left(43.5^{\circ}-49^{\circ} \mathrm{N}, 5^{\circ}-17^{\circ} \mathrm{E}\right)$. This may reduce the amplitude of the differences due to compensating effects. We can, however, examine individual basins where observed runoff data are available. Figure 15 shows a comparison between observed, CONT, and SUB runoff for three basins located in the Austrian region at different elevations-1686, 943, and $602 \mathrm{~m}$ as presented in Fig. 3 with the indications of A, B, and C, respectively. In the simulations runoff is locally calculated from the rain plus snowmelt rates and the soil water content (Dickinson et al. 1993). For the high-, mid-, and low-elevation basins the model runoff is averaged over upstream areas of 81,54 , and $135 \mathrm{~km}^{2}$, respectively, based on topographical information. This comparison is not intended to provide a general validation of runoff for Alpine catchments but it is more

simply aimed at investigating the different behavior of the CONT and SUB simulations at small basin scales.

Figure 15 shows that the CONT and SUB simulations exhibit a different behavior when the average runoff is computed over an area the typical size of an Alpine catchment or subcatchment. In the high-elevation site the peak observed runoff occurs in July (Fig. 15a), while at lower elevations it is found in May (Fig. 15b) and April (Fig. 15c). In the high-elevation basin both the CONT and SUB simulations show an earlier runoff peak than observed, however in the SUB simulation this occurs one month later in better agreement with the observations. In the midelevation basins, both simulations correctly capture the peak runoff month, however the SUB case shows a magnitude closer to observed. Finally, in the low-elevation basin the SUB simulation captures the observed peak runoff month, while in the CONT case this occurs one month earlier. Even if these are just illustrative examples, they clearly show how the subgrid 
(a) DJF

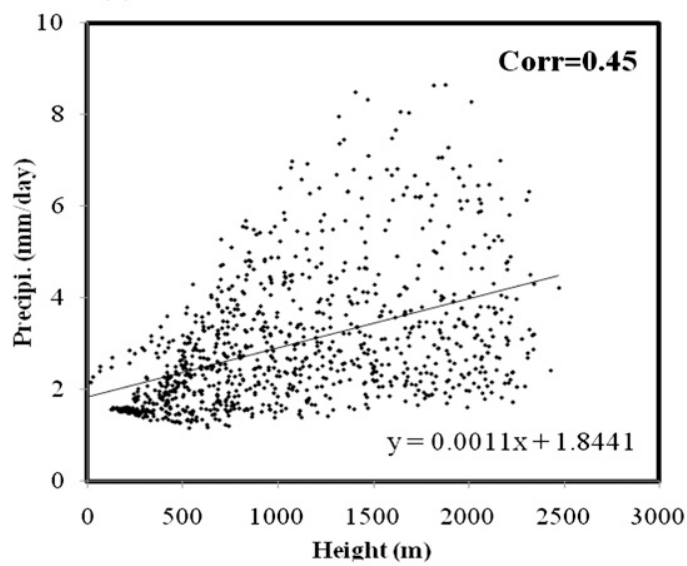

(c) JJA

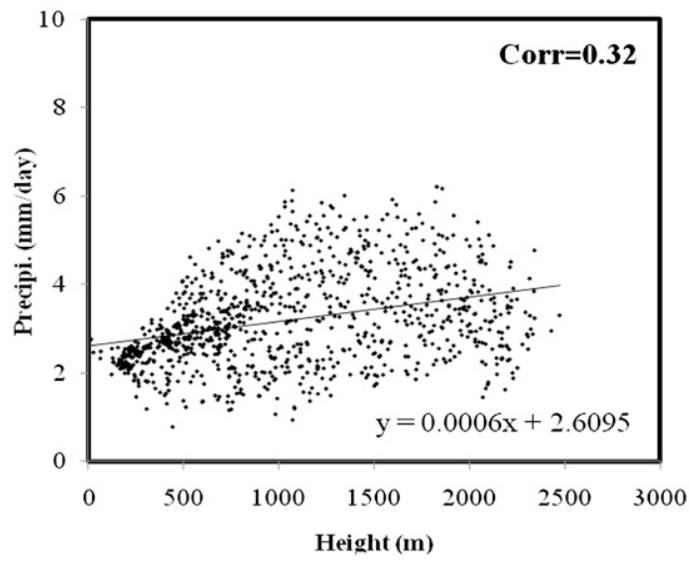

(b) MAM

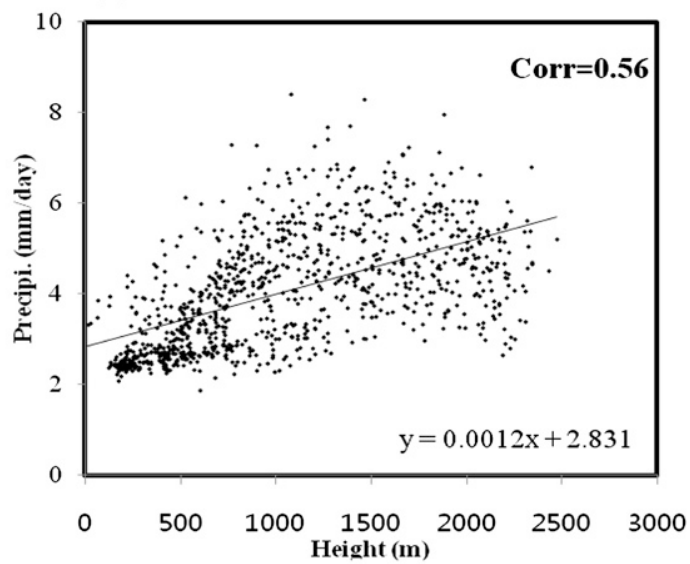

(d) $\mathrm{SON}$

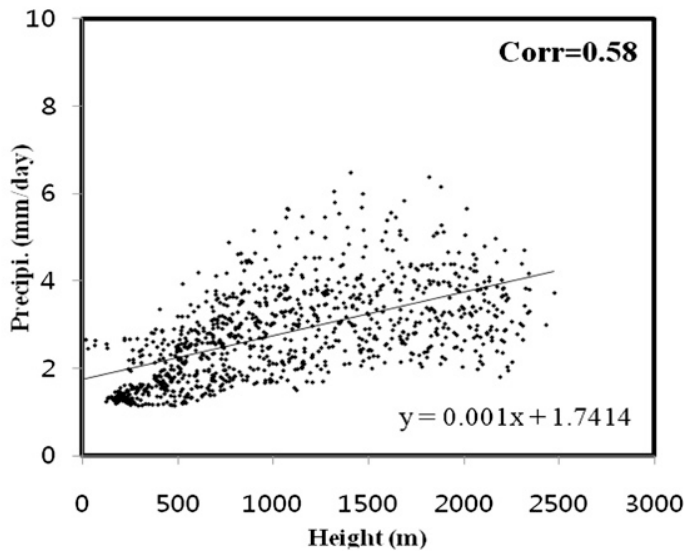

FIG. 17. Scatter diagram of the relationship between elevation and precipitation of 10 -yr climatology from the CONT simulation: (a) DJF, (b) MAM, (c) JJA, and (d) SON.

scheme, by a more refined representation of topography, can improve the simulation of the hydrologic cycle at the catchment basin level.

\section{Sensitivity of the subgrid scheme to different parametric assumptions}

\section{a. Model sensitivity to lapse rate}

The temperature disaggregation depends on the lapse rate used in Eq. (1). Following G03, in the reference simulation we employed an average lapse rate of $6.5^{\circ} \mathrm{C} \mathrm{km}^{-1}$. The lapse rate, however, can change with season and region, and this can in particular affect nonlinear and threshold surface processes such as snow formation and melting.

To assess the model sensitivity to the assumed temperature lapse rate, we performed a sensitivity experiment in which this was changed from $6.5^{\circ} \mathrm{C} \mathrm{km}^{-1}$ to the dry adiabatic lapse rate of $9.8^{\circ} \mathrm{C} \mathrm{km}^{-1}$, which thus con- stitutes an upper limit for this value. With this change, temperatures at subgrid high- (low) elevation points are lower (higher) than in the reference simulation. As mentioned, this sensitivity experiment is 16 months in length from September 1982 through December 1983, but the first 4 months are removed to allow for model spinup. Since the processes that may be expected to be particularly sensitive to the disaggregation lapse rate are snow formation and melting, Fig. 16 presents the monthly variation of the difference between the SUB and CONT snow depths over the Alps region applying the two different lapse rate values. To estimate the elevation dependence of the model sensitivity on the lapse rate, we examine five different elevation ranges.

From Fig. 16 we see that in the reference experiment (L6.5 in Fig. 16) the snow depths from the SUB simulation are consistently lower than those from the CONT simulation up to the 2000-m elevation, particularly in the late spring and early summer months. When the 2000-m threshold is reached, however, more snow is produced in 
(a) DJF [1983]

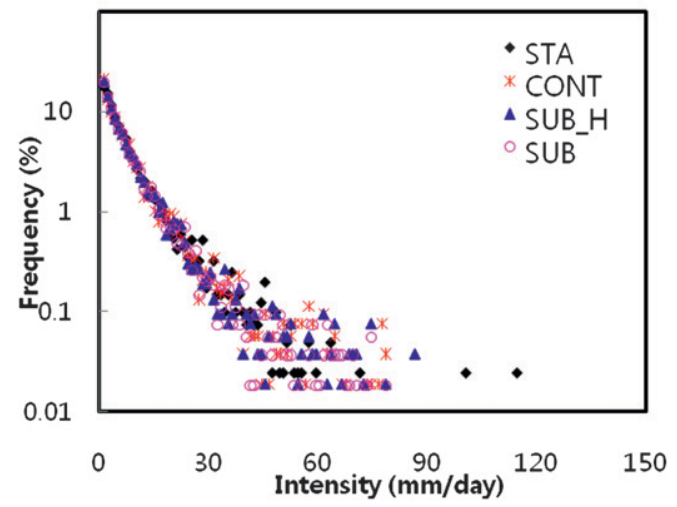

(b) JJA [1983]

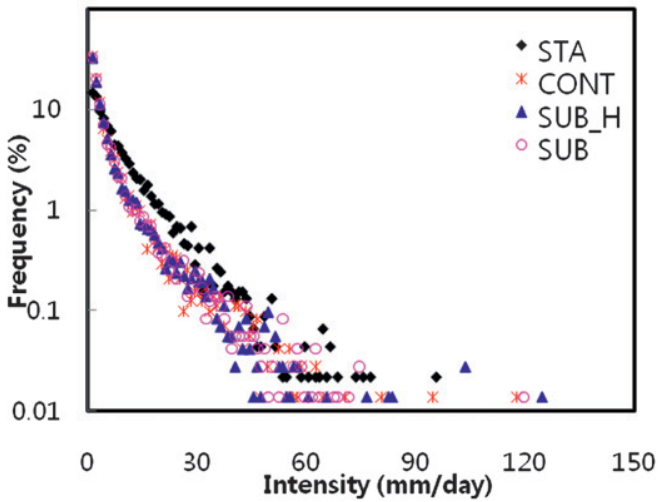

FIG. 18. Frequency distribution of daily precipitation for a 1-yr simulation (1983) over the Alps subdomain for the (a) winter and (b) summer seasons. Here, observations are obtained from the 145 stations in Fig. 3.

the SUB case between November and April, while still less is found in May-July. This indicates that at high elevations the SubBATS scheme tends to produce faster snow formation in the cold months and snowmelt in the warm months than the reference configuration. Moving our attention to the effect of the increased lapse rate, we first notice that this does not change the basic response induced by the presence of the subgrid scheme. In most cases, increasing the lapse rate tends to increase the amounts of snow, particularly at high elevations above $2000 \mathrm{~m}$. This is a direct consequence of the lower temperatures caused by the disaggregation at the highest peaks. At low elevations, the effect of the change in lapse rate is generally small.

We do not show here additional fields in the increased lapse rate experiment because the differences with the reference run were generally small. This sensitivity experiment thus suggests that, at least for the model configuration used here, the model is not very sensitive to the value of the lapse rate chosen for the disaggregation.

\section{b. Elevation-dependent disaggregation of precipitation}

In this section we test a precipitation disaggregation procedure based on an empirical relationship between precipitation and elevation. Because of the great variability in elevation gradient and the complex interactions between orography and weather systems, it is very difficult to obtain a general relationship between precipitation and elevation in the Alps (Barry 2008). However, an at least partial spatial coherence between precipitation and topography is found (Fig. 6), indicating increased precipitation along the high mountainous areas. Figure 17 shows a scatterplot of 10 -yr averaged precipitation versus topographical elevation for the four seasons and all the grid points of the Alps subdomain in the CONT simulation $(15 \mathrm{~km})$. Despite the pronounced scatter of the data, for all seasons a clear dependency of precipitation on elevation is found. Although more complex curves can be used, for simplicity we derive from the scatterplots a linear relationship between precipitation and elevation in the four seasons. This yields a correlation above $50 \%$ in fall and spring and $45 \%$ and $32 \%$ in winter and summer, respectively, all statistically significant at the $95 \%$ confidence level. A similar correlation is found for observed precipitation (not shown).

Even though this correlation could be scale dependent, based on this linear regression, as a first-order approximation we disaggregate the precipitation at the subgrid cells using the linear relationship empirically derived from the CONT simulation (SUB_H simulation in Table 1). Precipitation at a subgrid cell is thus determined using the following topographical correction:

$$
P_{s}=\bar{P}+\left[a\left(h_{s}-\bar{h}\right)\right],
$$

where $P_{s}$ is the subgrid precipitation, $\bar{P}$ is the CONT precipitation, $a$ is the slope coefficient derived from the empirical linear relationship (which varies with season), $h_{s}$ is the subgrid height, and $\bar{h}$ is the coarse-grid elevation. As with the previous sensitivity experiments, we test this disaggregation scheme in a 1-yr simulation (1983).

Figure 18 reports the frequency distribution of daily precipitation for the year 1983 over the Alpine region. The $15-\mathrm{km}$ control simulation (CONT), the $3-\mathrm{km}$ standard subgrid simulation (SUB), and the simulation with the new subgrid precipitation disaggregation (SUB_H) are compared with the Alpine station observations in the winter and summer seasons. The main effect in the SUB_H experiment is the occurrence of few intense precipitation events in the tail of the distribution in closer agreement with observations in the winter season. In the 
rest of the distribution the effect of the precipitation disaggregation scheme is small.

In Table 3 the root-mean-square error (RMSE) and spatial correlation for the two seasons are reported. The SUB_H simulation shows a slightly lower RMSE compared to the SUB and CONT simulations in both seasons and a slightly higher correlation in the summer. Therefore, although very crude, this first-order precipitation disaggregation scheme appears to slightly improve the simulation. On the other hand, further tests are required to fine-tune and generalize the approach.

\section{Summary and discussion}

In this study, we evaluate the performance of a mosaictype parameterization of subgrid-scale heterogeneity in topography and land use within the framework of the regional climate model, RegCM3. The subgrid scheme allows calculations of land surface processes to be performed on a regular finescale subgrid. In the application of the scheme, temperature, water vapor, and surface pressure are first disaggregated from the model grid to the subgrid according to the topographical information at the respective grids. Surface processes are then calculated on the subgrid and the surface fluxes are then reaggregated on the model grid and passed back to the atmospheric model.

We first validate a control 10-yr RegCM3 simulation (CONT) over a domain centered over the Alps and covering the central Mediterranean region at $15-\mathrm{km}$ grid spacing. The CONT simulation is then compared to a corresponding one (SUB) including the subgrid scheme at $3-\mathrm{km}$ grid spacing (25 subgrid points for each model grid box) to isolate its effects. The model is forced at the lateral boundaries by the NCEP reanalysis of observations, and the analysis is primarily focused on the surface variables, including the hydrologic cycle (i.e., the variable most affected by the subgrid scheme).

The validation of the CONT simulation first shows that the model reproduces well the climatology of the simulated region and period. Both the spatial and temporal patterns of temperature and precipitation over the Alps are well simulated, improving the previous performance of this modeling system. In particular the topographic forcing of the Alps on temperature and precipitation is well captured.

The subgrid scheme produces finer detail of temperature in response to the topographic disaggregation. Snow is also simulated with finer topographically induced detail and a comparison with station data shows that the elevation dependency of snow depths as well as the seasonal cycle of snow formation and melting are well reproduced (although the latter with a phase lag of about
TABLE 3. RMSE $\left(\mathrm{mm} \mathrm{day}^{-1}\right)$ and spatial pattern correlation coefficient of winter and summer precipitation against 145 station observations over Alps.

\begin{tabular}{llccc}
\hline & & CONT & SUB & SUB_H \\
\hline RMSE & DJF & 2.026 & 1.998 & 1.982 \\
& JJA & 1.110 & 1.122 & 1.052 \\
P-Corr & DJF & 0.543 & 0.551 & 0.559 \\
& JJA & 0.604 & 0.640 & 0.663 \\
\hline
\end{tabular}

one month, possibly tied to differences in the elevations of observing stations and closest model grid points). Precipitation and other components of the hydrologic cycle are not strongly affected by the subgrid scheme, however runoff at small catchment scales appears to be improved by the subgrid scheme. We finally present a sensitivity analysis of the subgrid scheme performance to different model parameters, such as temperature lapse rate and an empirical elevation-based disaggregation of precipitation.

A basic problem with the analysis of the performance of the subgrid scheme is the lack of sufficient stations to validate the model at the $3-\mathrm{km}$ scale. Our validation was based on a $25-\mathrm{km}$ gridded dataset and station data from Switzerland and Austria. However, clearly better finescale observational datasets are needed to evaluate models as they reach the sub-10-km scale. Despite these caveats the subgrid scheme in the configuration tested here appears to be a useful tool to provide first-order improved finescale information of surface processes for coupling with impacts models. We plan to use the present SUB model configuration with the elevationdependent disaggregation of precipitation for the generation of a new series of high-resolution climate change simulations and subsequent application to basin hydrology impact studies.

Acknowledgments. This work was completed as part of the ACQWA EU project as well as a research agreement with the Centro euroMediterraneo per I Cambiamenti Climatici (CMCC). We thank three anonymous reviewers for their constructive comments and suggestions, which helped to improve the quality of the paper.

\section{REFERENCES}

Adam, J. C., and D. P. Lettenmaier, 2003: Adjustment of global gridded precipitation for systematic bias. J. Geophys. Res., 108, 4257, doi:10.1029/2002JD002499.

Avissar, R., and R. A. Pielke, 1989: A parameterization of heterogeneous land surfaces for atmospheric numerical models and its impact on regional meteorology. Mon. Wea. Rev., 117,2113-2136.

Barry, R. G., 2008: Mountain Weather and Climate. 3rd ed. Cambridge University Press, 506 pp.

Christensen, O. B., J. H. Christensen, B. Machenauer, and M. Botzet, 1998: Very high-resolution regional climate simulations over Scandinavia-Present climate. J. Climate, 11, 3204-3229. 
Dickinson, R. E., 1995: Land-atmosphere interaction. Rev. Geophys., 33, 917-922.

— - A. Henderson-Sellers, and P. J. Kennedy, 1993: BiosphereAtmosphere Transfer Scheme (BATS) version 1 as coupled to the NCAR Community Climate Model. NCAR Tech. Note NCAR/TN-387+STR, 72 pp.

Dimri, A. P., 2009: Impact of subgrid scale scheme on topography and landuse for better regional scale simulation of meteorological variables over the western Himalayas. Climate Dyn., 32, doi:10.1007/s00382-008-0453-z.

Feddema, J. J., K. W. Oleson, G. B. Bonan, L. O. Mearns, L. E. Buja, G. A. Meehl, and W. M. Washington, 2005: The importance of land-cover change in simulating future climates. Science, $\mathbf{3 1 0}$, 1674-1678.

Frei, C., J. H. Christensen, M. Deque, D. Jacob, R. G. Jones, and P. L. Vidale, 2003: Daily precipitation statistics in regional climate models: Evaluation and intercomparison for the European Alps. J. Geophys. Res., 108, 4124, doi:10.1029/2002JD002287.

Giorgi, F., 2006: Regional climate modeling: Status and perspectives. J. Phys. IV, 139, 101-118.

— , and L. O. Mearns, 1991: Approaches to the simulation of regional climate change: A review. Rev. Geophys., 29, 191-216.

— effects in earth system modeling: Experience from land surface modeling. Rev. Geophys., 35, 413-438.

— , and L. O. Mearns, 1999: Introduction to special section: Regional climate modeling revisited. J. Geophys. Res., 104, 6335-6352.

— climate model. J. Geophys. Res., 105, 29 503-29 521.

— M. R. Marinucci, and G. T. Bates, 1993a: Development of a second-generation regional climate model (RegCM2). Part I: Boundary-layer and radiative transfer processes. Mon. Wea. Rev., 121, 2794-2813.

$\longrightarrow,-\longrightarrow$, and G. De Canio, 1993b: Development of a second-generation regional climate model (RegCM2). Part II: Convective processes and assimilation of lateral boundary conditions. Mon. Wea. Rev., 121, 2814-2832.

_ , R. Francisco, and J. Pal, 2003: Effect of a subgrid-scale topography and land use scheme on the simulation of surface climate and hydrology. Part I: Effects of temperature and water vapor disaggregation. J. Hydrometeor., 4, 317-333.

Grell, G. A., 1993: Prognostic evaluation of assumptions used by cumulus parameterizations. Mon. Wea. Rev., 121, 764-787.

Haylock, M. R., N. Hofstra, A. M. G. Klein Tank, E. J. Klok, P. D. Jones, and N. New, 2008: A European daily high-resolution gridded data set of surface temperature and precipitation for 1950-2006. J. Geophys. Res., 113, D20119, doi:10.1029/ 2008JD010201.

Holtslag, A. A. M., E. I. F. de Bruijin, and H. L. Pan, 1990: A high resolution air mass transformation model for short-range weather forecasting. Mon. Wea. Rev., 118, 1561-1575.

Im, E.-S., E.-H. Park, W.-T. Kwon, and F. Giorgi, 2006: Present climate simulation over Korea with a regional climate model using a one-way double-nested system. Theor. Appl. Climatol., 86, 187-200.

Kanamitsu, M., W. Ebisuzaki, J. Woollen, S.-K. Yang, J. J. Hnilo, M. Fiorino, and G. L. Potter, 2002: NCEP-DOE AMIP-II reanalysis (R-2). Bull. Amer. Meteor. Soc., 83, 1631-1643.

Kiehl, J. T., J. J. Hack, G. B. Bonan, B. A. Boville, B. P. Briegleb, D. L. Williamson, and P. J. Rasch, 1996: Description of NCAR Community Climate Model (CCM3). NCAR Tech. Note NCAR/TN-420+STR, 152 pp.

Leung, L. R., and S. J. Ghan, 1995: A subgrid parameterization of orographic precipitation. Theor. Appl. Climatol., 52, 95-118.

, and Y. Qian, 2003: The sensitivity of precipitation and snowpack simulations to model resolution via nesting in regions of complex terrain. J. Hydrometeor., 4, 1025-1043.

Pal, J. S., E. E. Small, and E. A. B. Eltahir, 2000: Simulation of regional-scale water and energy budgets: Representation of subgrid cloud and precipitation processes within RegCM. J. Geophys. Res., 105, 29 576-29 594.

— - and Coauthors, 2007: Regional climate modeling for the developing world: The ICTP RegCM3 and RegCNET. Bull. Amer. Meteor. Soc., 88, 1395-1409.

Pielke, R., 2001: Influence of the spatial distribution of vegetation and soils on the prediction of cumulus convective rainfall. Rev. Geophys., 39, 151-177.

_ - and R. Avissar, 1990: Influence of landscape structure on local and regional climate. Landscape Ecol., 4, 133-155.

Sasaki, H., and K. Kurihara, 2008: Relationship between precipitation and elevation in the present climate reproduced by the non-hydrostatic regional climate model. SOLA, $\mathbf{4}$, 109-112.

Seth, A., F. Giorgi, and R. E. Dickinson, 1994: Simulating fluxes from heterogeneous land surfaces: Explicit subgrid method employing the biosphere-atmosphere transfer scheme (BATS). J. Geophy. Res., 99, 18 651-18 667.

Wu, W., A. H. Lynch, and A. Rivers, 2005: Estimating the uncertainty in a regional climate model related to initial and lateral boundary conditions. J. Climate, 18, 917-933. 